\title{
A Systematic Literature Review of Blockchain-Enabled Supply Chain Traceability Implementations
}

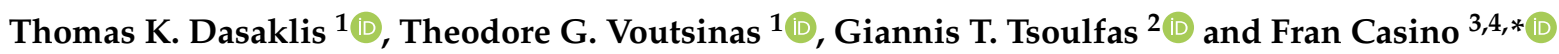 \\ 1 School of Social Sciences, Hellenic Open University, 26335 Patra, Greece; dasaklis@eap.gr (T.K.D.); \\ voutsinas.theodoros@ac.eap.gr (T.G.V.) \\ 2 Department of Agribusiness and Supply Chain Management, Agricultural University of Athens, \\ 32200 Thiva, Greece; giannis@aua.gr \\ 3 Department of Computer Engineering and Mathematics, Universitat Rovira i Virgili, 43007 Tarragona, Spain \\ 4 Information Management Systems Institute, Athena Research Center, 15125 Marousi, Greece \\ * Correspondence: francasino@unipi.gr
}

check for

updates

Citation: Dasaklis, T.K.;

Voutsinas, T.G.; Tsoulfas, G.T.; Casino, F. A Systematic Literature Review of Blockchain-Enabled Supply Chain Traceability Implementations. Sustainability 2022, 14, 2439. https://doi.org/10.3390/ su14042439

Academic Editors: Marc A. Rosen and Alessio Ishizaka

Received: 21 January 2022

Accepted: 17 February 2022

Published: 20 February 2022

Publisher's Note: MDPI stays neutral with regard to jurisdictional claims in published maps and institutional affiliations.

Copyright: (c) 2022 by the authors. Licensee MDPI, Basel, Switzerland. This article is an open access article distributed under the terms and conditions of the Creative Commons Attribution (CC BY) license (https:// creativecommons.org/licenses/by/ $4.0 /)$.

\begin{abstract}
In recent years, traceability systems have been developed as practical tools for improving supply chain (SC) transparency and visibility, especially in health and safety-sensitive sectors like food and pharmaceuticals. Blockchain-related SC traceability research has received significant attention during the last several years, and arguably blockchain is currently the most promising technology for providing traceability-related services in SC networks. This paper provides a systematic literature review of the various technical implementation aspects of blockchain-enabled SC traceability systems. We apply different drivers for classifying the selected literature, such as (a) the various domains of the available blockchain-enabled SC traceability systems and relevant methodologies applied; (b) the implementation maturity of these traceability systems along with technical implementation details; and (c) the sustainability perspective (economic, environmental, social) prevalent to these implementations. We provide key takeaways regarding the open issues and challenges of current blockchain traceability implementations and fruitful future research areas. Despite the significant volume and plethora of blockchain-enabled SC traceability systems, academia has so far focused on unstructured experimentation of blockchain-associated SC traceability solutions, and there is a clear need for developing and testing real-life traceability solutions, especially taking into account feasibility and cost-related SC aspects.
\end{abstract}

Keywords: supply chain; traceability; blockchain; sustainability

\section{Introduction}

Global production networks have adopted supply chains (SCs) as a generic organizational model [1]. SC management is considered a critical inter-organizational mechanism for creating a competitive advantage, particularly in the context of supplier and consumer alliances and networks. Organizational interdependence is emphasized in SC management, with firms working together to achieve SC efficiency [2]. Customers' numerous demands, such as increased flexibility, velocity, information, and product traceability, have fueled the growth of SCs in recent years. This phenomenon can be explained by several factors, including the acceleration of technological innovations, which allow for better system and process performance; globalisation of trade, which allows customers faster access to products; and environmental responsibility, which prompts customers to inquire about the long-term viability of their purchases [3]. Due to globalisation, fluctuating client expectations, expanded product lines, uncertainty about supplier performance, and a slew of other parameters, SC networks have become more complex, increasing commodities and goods' production and movement across geographically disparate locations [4]. Contemporary SCs are organically diverse, with multi-echelon, geographically dispersed companies that struggle to service clients. Due to numerous regulating tactics, globalization, and distinct 
cultural and behavioral traits in this complex network, assessing data and managing risk in SC networks is challenging. Ineffective transactions, pilferage, fraud, and poor SC execution lead to a loss of confidence, which is why SC members require improved data interchange and verifiability [5].

Therefore, it is becoming more difficult to trace every step of a product's journey back to its production source. Some SC areas may be particularly dark due to multiple actors and multi-layer structures with different systems and requirements. The management culture employed in modern SCs has an influence on the final product's quality, the quality of service along the SC, and the viability of the enterprises involved. The employment of modern technical methods to manage a SC offers significant benefits that improve SC resilience [6-8]. In recent years, traceability systems have been developed as effective tools for improving SC transparency, especially in globalised SC networks. Such systems have gained widespread acceptance among consumers, business managers, public policymakers, and special interest groups as critical tools for ensuring the safety and quality of products, especially in health and safety-sensitive sectors like food and pharmaceuticals [9]. Traceability systems provide the means for SC networks to meet regulatory requirements, connect with and understand the various actors upstream in the SC, inform consumers about the provenance and origin of products, enhance consumer confidence, and meet customer requirements. Traceability can positively impact the market, reduce risks, liability claims, and lawsuits, and safeguard the integrity of processes within SC networks. SC traceability systems offer significant operational advantages, especially in the case of product recalls. Moreover, companies can identify opportunities for improvements in the whole SC, identify and eliminate the unnecessary intermediaries, and plan more effectively in the long term by gathering and analysing more detailed information on SC performance metrics [10].

With the advancement of economic globalization, SC competition is becoming more prevalent. Because of the massive and growing use of natural resources and the consequent environmental impacts, sustainable development is a significant subject that receives great attention from the industrial and academic sectors [11]. There is a continuing debate about the developed world's development and advancement of global value chains, as well as their impact on emerging economies, which results in various sustainability concerns. In today's linked global economy, the necessity for inter-organizational communication is critical [12]. Companies have been pushed to build their SCs to account not only cost but also other variables as a result of emerging concerns and new challenges brought on by globalization [13]. Investors, customers, and governments are all looking for products and processes that are more environmentally friendly, and certifications that back up these claims are becoming increasingly common. In particular, companies are under pressure from governments, consumers, NGOs, and other stakeholders to disclose sufficient information about their products' origin and provenance, composition, and production conditions [14]. The reputational cost of failing to meet the demands of a socially conscious business can be significant [15]. Traceability in sustainability allows a company to make and verify sustainability claims with greater credibility and transparency. A sustainable product system relies on traceability to verify social and environmental claims (such as organic certification, carbon neutrality, and the absence of child labour). Still, this verification cannot be provided solely by traceability. To achieve their sustainability objectives, SC partners must clearly define their goals, incorporate appropriate data capture and validation methods into their approach, and choose the right technology to meet their requirements. Transparency in a SC also lessens reputational-related risks and improves the reliability of business operations.

The ongoing digitisation of SC processes offers new ways and tools for establishing sound traceability systems. For instance, companies increasingly rely on the Internet of Things (IoT) applications to improve SC traceability processes. RFID, sensors, and wireless technologies have recently provided traceability and monitoring solutions throughout SC networks. IoT technologies enable automatic SC tracking at near-zero operational costs. IoT systems may read data from a variety of devices, including smart tags (RFIDs, NFC, 
barcodes, bluetooth low energy, laser scanners, and other information sensing devices and intelligent embedded technologies), as well as sensory data such as ambient temperature and humidity, vehicle speed, and geolocation [16]. IoT-related traceability in the SC comes with many benefits, including temperature regulation and more accurate tracking, better quality control, safety, SC process optimisation, and reduced costs, especially in the case of product recalls [9].

Specialised traceability solutions at the intersection of IoT and blockchain technologies are expected to improve trust and transparency in global SC networks. Blockchain is the technology that underpins all cryptocurrencies and was first introduced as the underlying technology of the Bitcoin digital currency. In general, a blockchain may be considered an append-only distributed database, specifically referred to as a ledger where records of all transactions occurring in a peer-to-peer network may be stored in blocks [17]. For achieving the necessary agreement on the state of the network, mainly which transactions are legitimate and should be added to the blockchain, the nodes use fault-tolerant mechanisms, also known as consensus mechanisms. These mechanisms provide a non-partisan means of ensuring that only the true state of the network is maintained, and they further safeguard the validity of transactions taking place within the network. Various consensus mechanisms exist; however, Proof of Work and Proof of Stake are the most common and extensively used consensus mechanisms across a plethora of real-life blockchain applications [18]. Within a blockchain network, users can deploy software known as smart contracts. Smart contracts are computer code running on top of a blockchain network and can be thought of as a digitised version of traditional contracts. The code of the smart contract is automatically executed once predetermined rules/conditions are met [19]. Smart contracts offer additional functionalities in blockchain networks because they foster transaction credibility, automation and efficiency [17].

\section{Motivation and Contribution}

Blockchain-related SC traceability research has received significant attention during the last several years, and arguably blockchain is currently the most promising technology for providing traceability-related services in SC networks. Many review papers exist in the literature concerning blockchain-enabled SC traceability. Specific attention has been paid so far in blockchain-related traceability systems in agri-food supply and agricultural products $[16,20]$. Other authors have focused on blockchain-enabled traceability systems in the gems industry [21]. It is worth noting that none of these studies cover either the technical and/or implementation details or the implementation maturity of the relevant blockchain-enabled SC traceability systems. From a technical perspective, the authors in [22] provide an overview of user interface characteristics of blockchain-enabled traceability systems. We managed to retrieve one paper similar to our approach [23]. In particular, the authors explore the technical aspects of blockchain-related implementation platforms in SC traceability. However, they focus solely on agricultural systems. In Table 1 we present the various features and scope of similar review papers and the scope/purpose of our survey paper. 
Table 1. List of blockchain-related SC traceability review papers. The implementation details column denotes a qualitative analysis of the technologies and tools used. The maturity analysis column denotes the analysis of the technology readiness level of the implementations.

\begin{tabular}{|c|c|c|c|c|}
\hline Reference & Domain & $\begin{array}{l}\text { Implementation } \\
\text { Details }\end{array}$ & $\begin{array}{l}\text { Maturity } \\
\text { Analysis }\end{array}$ & Purpose \\
\hline [16] & Agri-food & - & - & $\begin{array}{l}\text { Methods, benefits, and challenges of } \\
\text { blockchain-based agri-food traceability systems. }\end{array}$ \\
\hline [20] & Agriculture/agri-food & $\checkmark$ & - & $\begin{array}{l}\text { Integration of blockchain into traceability systems, } \\
\text { existing commercial applications, challenges, and } \\
\text { future prospects of the application of blockchain } \\
\text { technologies in the agri-food SC. }\end{array}$ \\
\hline [21] & Gem & - & - & $\begin{array}{l}\text { Current trends and developments in the tracking } \\
\text { and traceability of gems. }\end{array}$ \\
\hline$[22]$ & Agri-food & - & - & $\begin{array}{l}\text { User interface characteristics of blockchain-enabled } \\
\text { traceability systems. }\end{array}$ \\
\hline [23] & Agriculture/agri-food & $\checkmark$ & - & $\begin{array}{l}\text { Techniques and applications (platforms, smart } \\
\text { contracts) of blockchain technology used in the } \\
\text { agricultural sector and relevant implementation } \\
\text { challenges. }\end{array}$ \\
\hline Our review & All domains & $\checkmark$ & $\checkmark$ & $\begin{array}{l}\text { Taxonomy of blockchain-specific SC traceability } \\
\text { implementations based on the various domains, the } \\
\text { methodologies applied, implementation maturity, } \\
\text { and the sustainability perspective covered. } \\
\text { Challenges and open issues prevalent to } \\
\text { blockchain-specific SC traceability } \\
\text { implementations. }\end{array}$ \\
\hline
\end{tabular}

Therefore, it is evident that a comprehensive appraisal of the various technical implementation aspects of blockchain-enabled SC traceability systems and their sustainability perspective is still missing from the literature. To this end, we provide a systematic survey of the various blockchain-enabled SC traceability systems with a specific focus on the maturity of their implementation status. More specifically, we apply different drivers for classifying the selected literature, such as (a) the various domains of the available blockchain-enabled SC traceability systems and relevant methodologies applied; (b) the implementation maturity of these traceability systems along with technical implementation details; and (c) the sustainability perspective (economic, environmental, social) prevalent to these blockchain-enabled SC traceability implementations. Therefore, the main contributions of this paper are the following:

1. We present a detailed taxonomy of the available blockchain-specific SC traceability implementations. In particular, we classify these implementation approaches based on the various domains, the methodologies applied, and their sustainability perspective covered.

2. Based on the above classification scheme, we outline all the available blockchainspecific SC traceability implementations identified, their technical characteristics, and implementation maturity details (blockchain platforms used, relevant DApps, etc.).

3. We discuss various issues prevalent to blockchain-specific SC traceability implementations, as well as research gaps and open issues that remain unaddressed.

The rest of the paper is organised as follows. In Section 3 we present the methodology adopted for conducting our systematic review. The classification of the available literature is presented in Section 4. In Section 5 we report on the key findings of our research, and we discuss various challenges and open issues prevalent to blockchain-specific SC traceability implementations. The paper ends with some concluding remarks. 


\section{Research Methodology}

This section outlines the methodology adopted for carrying out our systematic literature review. For conducting our review, we have used various features from the approach presented in [24]. As seen in Figure 1, our review protocol consists of five steps (and three phases respectively): (1) Plan and define the scope of the review, (2) Database search, (3) Apply inclusion and exclusion criteria, (4) Perform content analysis, and (5) Synthesise and report the results of the survey.

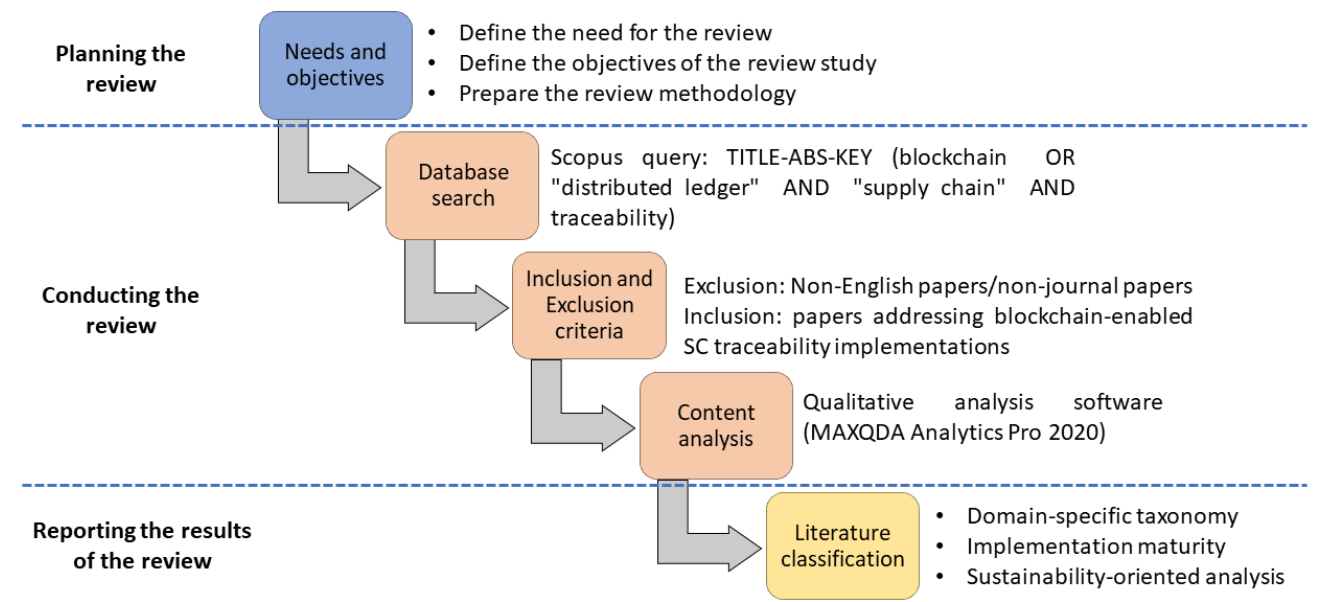

Figure 1. Methodological framework adopted for conducting our systematic literature review.

\subsection{Definition of the Scope of the Review}

A systematic literature review relies on standardised processes for searching, screening, analysing, and synthesising the available literature within a specific domain. In addition, the goal of any systematic review is to synthesise the available literature in a systematic, transparent, and reproducible manner, thus assisting in the development of policy and decision-making [25]. Systematic reviews help practitioners/managers build a reliable knowledge base by aggregating information from a wide range of relevant studies [25].

This paper focuses on the available blockchain-enabled SC traceability implementations found in the literature. Our overall approach relies on several predefined research questions pertinent to blockchain-enabled SC traceability implementations, which are clearly tied to the specific objectives of our paper (see Table 2). Based on these research questions, we performed a thorough analysis of the available literature for appraising the various technical implementation aspects of blockchain-enabled SC traceability systems with a specific focus on the maturity of these implementations. Our main research questions $(\mathrm{RQ})$ are summarised in Table 2.

\subsection{Search Strategy}

Our overall search strategy relied on the Scopus scientific database for finding relevant papers. To this end, we performed a systematic search during November 2021 without time-frame restrictions. We used a predefined set of terms for searching within the titles, abstracts, and keywords of all the available Scopus papers. The terms used included the following "TITLE-ABS-KEY (blockchain OR "distributed ledger" AND "supply chain" AND traceability)".

\subsection{Application of Inclusion and Exclusion Criteria}

We evaluated the eligibility of the retrieved literature (in total, 668 papers) based on a set of inclusion/exclusion criteria. Initially, we excluded all the papers written in languages other than English from Scopus. In what follows, we included only peer-reviewed research 
articles published in scientific journals (therefore, we excluded all papers published in conference proceedings, book chapters, editorials, etc.). The next step included screening the retrieved papers (title and abstract reading). For the remaining papers, we performed a full reading. It is worth noting that several papers were excluded during the last two steps (Title/Abstract screening and full paper reading). For example, we excluded many theoretical papers describing either high level-architectures or concept models/frameworks of blockchain in SC traceability. In addition, we excluded policy-oriented papers and other papers reporting theoretical findings of the importance of blockchain in SC traceability (critical success factors, empirical papers, qualitative studies, etc.). Therefore, we included only research papers reporting blockchain-related SC traceability implementations (72 papers).

Table 2. Research questions and objectives of the survey.

\begin{tabular}{ll}
\hline Research Questions & Objectives \\
\hline $\begin{array}{l}\text { RQ1: Are there any domain-specific aspects related to the } \\
\text { maturity of the blockchain-enabled SC traceability imple- }\end{array}$ & $\begin{array}{l}\text { To provide a mapping of the available blockchain-related SC trace- } \\
\text { ability implementation frameworks along with their characteristics } \\
\text { (methodologies adopted, product-specific classification etc). }\end{array}$ \\
\hline $\begin{array}{l}\text { RQ2: What is the current status in terms of maturity imple- } \\
\text { mentation of the available blockchain-specific SC traceability }\end{array}$ & $\begin{array}{l}\text { To provide a sound classification of the technical characteristics of } \\
\text { the available blockchain-specific SC traceability implementations } \\
\text { systems? }\end{array}$ \\
\hline $\begin{array}{l}\text { RQ3: Is the sustainability perspective prevalent within these } \\
\text { blockchain-enabled SC traceability implementations? }\end{array}$ & $\begin{array}{l}\text { To define to what extent the available blockchain-related SC trace- } \\
\text { ability implementation frameworks capture the three dimensions } \\
\text { of sustainability (economic, environmental, social). }\end{array}$ \\
\hline $\begin{array}{l}\text { RQ4: What are the main challenges for actually implement- } \\
\text { ing blockchain-enabled SC traceability systems as derived } \\
\text { by the available literature? }\end{array}$ & $\begin{array}{l}\text { To derive and classify current challenges prevalent to the } \\
\text { blockchain-related SC traceability implementation frameworks and } \\
\text { to derive fruitful areas for future research. }\end{array}$ \\
\hline
\end{tabular}

\subsection{Content Analysis}

The thematic content analysis enables the descriptive presentation of qualitative data and, therefore, helps researchers identify, analyse, and interpret patterns of meaning (or "themes") within qualitative data [26,27]. We have adopted a thematic content analysis approach for deriving research areas and common themes from the eligible literature. We used a qualitative analysis software for the thematic content analysis of the selected literature (MAXQDA2020).

\subsection{Synthesis and Reporting}

We adopted various qualitative analysis methods such as narrative synthesis to classify and synthesise the extracted data. Narrative synthesis combines the findings from multiple studies in a qualitative manner. Narrative synthesis focuses on how studies addressing a different aspect of the same phenomenon can be narratively summarised and built up to provide a bigger picture of that phenomenon. Narrative synthesis is largely a process of compiling descriptive data and exemplars from individual studies and building them into a mosaic or map [28]. In addition, we have used various ways to synthesise the available literature to report the results of our study in a sound and comprehensive manner. For example, we present multiple categorisations of the available blockchain-enabled SC traceability implementations based on (a) the specific SC domain and product/service in which they are applied, (b) relevant methodologies used, (c) the sustainability perspective covered, and (d) their technical features.

\subsection{Bibliographic Analysis}

In what follows, we present a descriptive analysis of the selected papers included in our analysis. The descriptive analysis includes 72 peer-reviewed research articles published between 2018 and 2021 (as of November). The goal of the proposed descriptive analysis is threefold: 
1. It improves the statistical description, grouping, and presentation of the relevant literature's constructs of interest or their relationships (publications per year and domain, etc.).

2. It includes an analysis of current research trends in the field of blockchain-enabled SC traceability systems as well as a discussion of the issues that have been found. As a result, it backs up the taxonomy described in Section 4.

3. It allows us to visually demonstrate the diverse research approaches used up to this point in the scientific literature regarding the proliferation of blockchain-enabled SC traceability systems and their implementation status.

The distribution of publications over time is depicted in Figure 2. In particular, Figure 2 shows a year-by-year analysis of the selected papers. It is worth noting that the number of publications has increased significantly since 2020. In the last two years, there has been an explosion of blockchain research in the field of SC traceability. Until the end of 2019, only 12 papers described blockchain-specific SC traceability implementations. However, since 2020, the number of papers published in the scientific literature has risen to nearly 50. Note that the final number of papers appearing in Scopus for 2021 will be eventually higher (due to listing/indexing lag). Therefore, research in blockchain and SC traceability has slowly but steadily increased over the last couple of years. This upward trend reflects blockchain's essential public and policy impact on SC traceability.

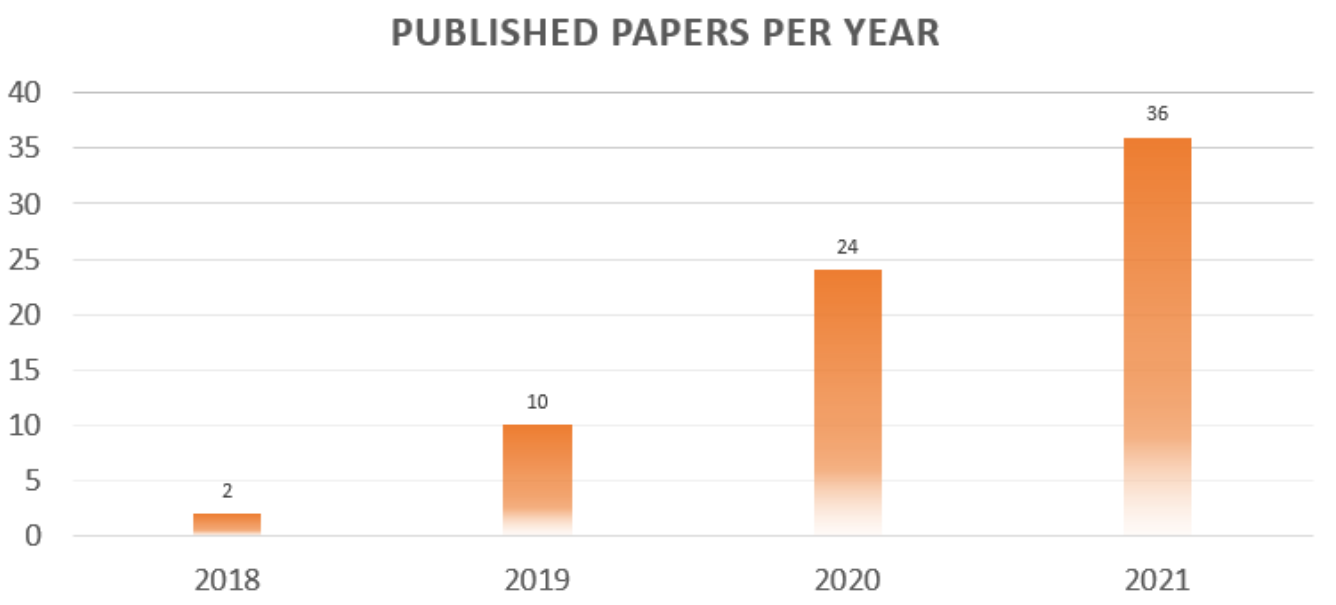

Figure 2. Distribution of publications per year.

Figure 3 shows the domain-specific distribution of the 72 peer-reviewed papers included in our analysis. It is worth noting that we have identified ten (10) prevalent areas of research interest in blockchain-enabled SC traceability implementations: SC (generic), pharmaceuticals, manufacturing, food, electronics, construction, aviation, automobile industry, apparel, and agriculture/agri-food. The SC (generic) category attracts most of the current research attention (20 out of the 72 papers), followed by food (17 out of 72), agriculture/agri-food (13 out of 72), and pharmaceuticals (11 out of 72). This distribution highlights the importance of traceability in safety-sensitive sectors (agriculture, food, and pharmaceuticals) where customers, partners, and other stakeholders are increasingly demanding greater access to information about a company's multi-tier SC.

In Table 3 we present the peer-reviewed journals in which the selected papers were published. It is worth noting that 19 out of the 72 papers $(26 \%)$ were published in IEEE Access. Other journals for blockchain-enabled SC traceability systems include Computers and Industrial Engineering, Sensors, Applied Sciences, International Journal of Advanced Computer Science, and Applications and Sustainability. Therefore, most retrieved papers have been published in IT-oriented and not managerial journals. 


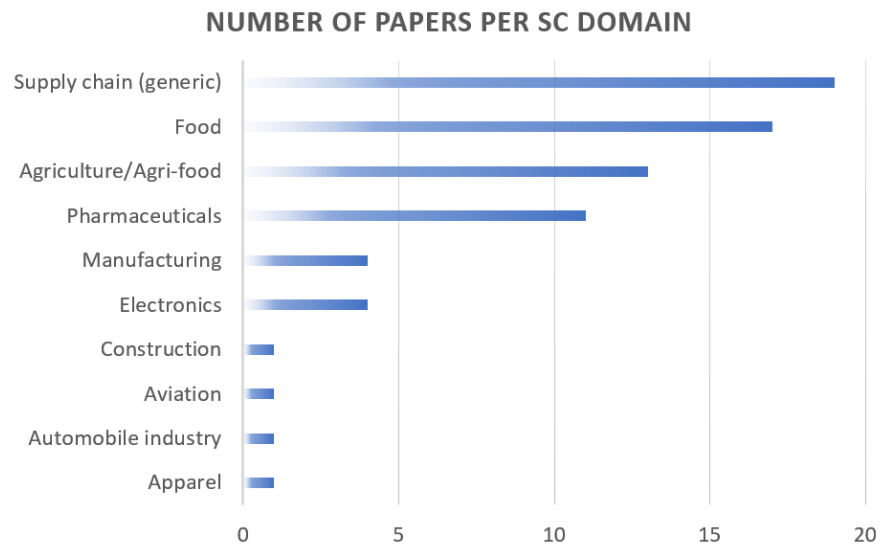

Figure 3. Domains of blockchain-specific SC traceability implementations.

Table 3. Distribution of journal sources of the selected literature.

\begin{tabular}{|c|c|}
\hline Journal & $\begin{array}{c}\text { Number of Papers } \\
\text { Published }\end{array}$ \\
\hline IEEE Access & 19 \\
\hline Computers and Industrial Engineering & 4 \\
\hline Sensors & 4 \\
\hline Applied Sciences & 3 \\
\hline International Journal of Advanced Computer Science and Applications & 3 \\
\hline Sustainability & 3 \\
\hline International Journal of Information Management & 2 \\
\hline ACM Transactions on Design Automation of Electronic Systems & 1 \\
\hline Acta Agriculturae Scandinavica Section B: Soil and Plant Science & 1 \\
\hline Advances in Science, Technology and Engineering Systems & 1 \\
\hline Automation in Construction & 1 \\
\hline Canadian Journal of Electrical and Computer Engineering & 1 \\
\hline Cluster Computing & 1 \\
\hline Computers and Electronics in Agriculture & 1 \\
\hline Computers in Industry & 1 \\
\hline Digital Communications and Networks & 1 \\
\hline Electronics & 1 \\
\hline Energies & 1 \\
\hline Expert Systems with Applications & 1 \\
\hline Future Internet & 1 \\
\hline ICT Express & 1 \\
\hline IEEE Transactions on Industrial Informatics & 1 \\
\hline Informatics & 1 \\
\hline Information and Management & 1 \\
\hline Intelligent Systems in Accounting, Finance and Management & 1 \\
\hline International Journal of Circuits, Systems and Signal Processing & 1 \\
\hline International Journal of Computational Science and Engineering & 1 \\
\hline International Journal of Information Technology & 1 \\
\hline International Journal of Pharmaceutics & 1 \\
\hline International Journal of Production Research & 1 \\
\hline International Journal of Web Information Systems & 1 \\
\hline IT Professional & 1 \\
\hline Journal of Food Process Engineering & 1 \\
\hline Journal of Manufacturing Systems & 1 \\
\hline PeerJ Computer Science & 1 \\
\hline Personal and Ubiquitous Computing & 1 \\
\hline Robotics and Computer-Integrated Manufacturing & 1 \\
\hline SAE International Journal of Transportation Cybersecurity and Privacy & 1 \\
\hline Security and Communication Networks & 1 \\
\hline Sustainable Cities and Society & 1 \\
\hline Transactions on Emerging Telecommunications Technologies & 1 \\
\hline
\end{tabular}




\section{Classification of the Retrieved Literature}

In what follows, we present the classification and analysis of the selected literature (72 papers). As already noted, we have identified ten (10) thematic areas of research interest in blockchain-enabled SC traceability implementations (see Figure 3). In addition, we derive key technical characteristics and the implementation maturity of the available blockchain-related SC traceability systems.

\subsection{Taxonomy}

\subsubsection{Supply Chain (Generic)}

In [29], the authors propose a permissioned blockchain-based double-layer framework for product traceability. The framework's double-layer design is based upon the usage of smart contracts. The authors run simulation tests to evaluate the performance of the proposed framework in assisting inventory management processes. In [30], the authors present an Industry 4.0 inventory and traceability system using an unmanned aerial vehicle and blockchain technology. The proposed system collects and processes inventory data in real-time while safeguarding the security and redundancy of the available data. Using a real-world warehouse application, the suggested system was found to be far faster than a human operator in gathering inventory data. The work presented in [31] discusses an end-to-end wood traceability system based on the Microsoft Azure blockchain technology and smart contracts. In [32], the authors use ontologies for developing smart contracts that execute a provenance trace and enforce traceability constraints on the Ethereum blockchain platform.

Some interesting blockchain-based traceability systems are applied in the retail industry. For example, a distributed and transparent ledger system is examined for various e-commerce products, including health drugs, electronics, security appliances, food products, etc. The proposed solution is advantageous for improving product traceability and assuring social and financial sustainability [33]. In [34] the authors propose a commodity tracing system based on blockchain that uses smart contracts. The system permanently saves all commodity history in a global database, forming a chain that can be traced back to the source of products. The authors in [35] develop a Quorum-based prototype for tracing furniture. They perform a series of tests to determine their solution's maximum throughput and average transaction processing time on different transaction loads. In [36] the authors design and test a product traceability system in which all product transferring histories are perpetually recorded in a distributed ledger using smart contracts. Of particular interest is the usage of blockchain tokens for establishing SC traceability systems. In [37] the authors present a blockchain-based SC management system that allows for the tracing and tracking of commodities, as well as their transformation during the manufacturing process, utilising smart contracts and tokens. In particular, using a "token recipe", they define the amount of tokenised commodities required for minting a new token to create a link between a product and the components required to produce it. They showcase the applicability of their approach using the Ethereum Virtual Machine (EVM). Finally, in [38] the authors use blockchain technology to create a quality control system for wind turbine blades. The system ensures product's quality by allowing various stakeholders (e.g., regulators and other SC participants) to verify quality-related data.

Other authors use blockchain technology as leverage for developing sound SC risk management approaches. For instance, in [39] the authors combine blockchain and a real-time event-monitoring system to track and disseminate emergent knowledge for preemptive management purposes. To improve visibility, the authors in [40] propose a blockchain-based SC network model. The proposed model consists of platforms for information sharing, traceability, and inventory visibility based on smart contracts. Similar approaches are described in [41-43] where the authors use blockchain technology for tracking and sharing critical SC information among the various stakeholders involved. The usage of blockchain technology has been proposed in the case of vendor managed inventory (VMI). The authors in [44] present a blockchain-based approach for tracking VMI 
SC operations. Their system captures interactions among stakeholders based on Ethereum smart contracts and decentralised storage systems.

Blockchain-related traceability solutions have been proposed in the case of reverse SC. A blockchain-based solution to automate forward processes and establish data provenance for COVID-19 medical equipment and waste disposal is described in [45]. The authors use the Ethereum blockchain platform in conjunction with the InterPlanetary File System (IPFS) (https:/ /ipfs.io/, accessed on 10 December 2021) decentralised storage to create a reliable, traceable, transparent, and auditable solution for the forward and waste management of COVID-19 medical equipment. A cost-benefit analysis shows the proposed solution's performance to be affordable. Using the integrated Triple Retry framework, the authors in [46] design and test a circular blockchain platform to bridge the three circular SC reverse processes (i.e., recycling, redistribution, and re-manufacturing). A similar approach is presented in [47], where the authors develop an e-waste management system using blockchain technology and smart contracts. In Table 4 we present a comparison of the different features extracted from the generic SC literature.

Table 4. Comparison of the different features extracted from the generic supply chain literature.

\begin{tabular}{|c|c|c|c|}
\hline Source & Methodology & Product & Sustainability Perspective \\
\hline [45] & $\begin{array}{l}\text { Architecture development, system design/testing, } \\
\text { simulation, cost benefit analysis, security analysis }\end{array}$ & Medical supplies & Environmental \\
\hline [29] & $\begin{array}{l}\text { Architecture development, system c design/testing, } \\
\text { performance evaluation, security analysis }\end{array}$ & Agnostic & Social, economic \\
\hline [30] & $\begin{array}{l}\text { Architecture development, system design/testing, } \\
\text { performance analysis }\end{array}$ & Warehouse management & Undefined \\
\hline [31] & $\begin{array}{l}\text { Architecture development, system design/testing, } \\
\text { performance analysis }\end{array}$ & Wood & Economic \\
\hline [32] & $\begin{array}{l}\text { Ontologies, architecture development, system de- } \\
\text { sign/testing }\end{array}$ & Agnostic & Undefined \\
\hline [33] & $\begin{array}{l}\text { Architecture development, system design/testing, } \\
\text { performance evaluation }\end{array}$ & E-products & Social, economic \\
\hline [34] & $\begin{array}{l}\text { Architecture development, system design/testing, (in- } \\
\text { formal) security analysis }\end{array}$ & Goods & Social \\
\hline [39] & $\begin{array}{l}\text { Architecture development, system design/testing, } \\
\text { performance evaluation, cost analysis }\end{array}$ & Goods & Economic \\
\hline [41] & $\begin{array}{l}\text { Architecture development, system design/testing, } \\
\text { performance evaluation }\end{array}$ & Agnostic & Economic \\
\hline [42] & Architecture development, system design/testing & Agnostic & Social \\
\hline [43] & $\begin{array}{l}\text { Architecture development, system design/testing, } \\
\text { performance evaluation, security analysis }\end{array}$ & Agnostic & Social, economic \\
\hline [40] & $\begin{array}{l}\text { Architecture development, system design/testing, } \\
\text { performance evaluation }\end{array}$ & Agnostic & Economic \\
\hline [44] & $\begin{array}{l}\text { Architecture development, system design/testing, } \\
\text { performance evaluation, cost analysis, security analy- } \\
\text { sis, comparison analysis }\end{array}$ & Agnostic & Social, economic \\
\hline [46] & Architecture development, system design & Agnostic & $\begin{array}{l}\text { Social, economic, } \\
\text { environmental }\end{array}$ \\
\hline [47] & $\begin{array}{l}\text { Architecture development, system design/testing, } \\
\text { performance analysis, security analysis }\end{array}$ & E-products, e-waste products & $\begin{array}{l}\text { Social, economic, } \\
\text { environmental }\end{array}$ \\
\hline [35] & $\begin{array}{l}\text { Case study, architecture development, system de- } \\
\text { sign/testing, performance analysis }\end{array}$ & Furniture & Undefined \\
\hline
\end{tabular}


Table 4. Cont.

\begin{tabular}{clcc}
\hline Source & Methodology & Product & Sustainability Perspective \\
\hline [36] & $\begin{array}{l}\text { Architecture development, system design/testing, } \\
\text { performance analysis, cost analysis, comparison anal- } \\
\text { ysis }\end{array}$ & Agnostic & Social \\
\hline [37] & $\begin{array}{l}\text { Architecture development, system design/testing, } \\
\text { performance analysis, cost analysis }\end{array}$ & Agnostic/generic products & Social \\
\hline [38] & $\begin{array}{l}\text { Architecture development, system design/testing, } \\
\text { performance analysis }\end{array}$ & Wind turbine blade & Social, environmental \\
\hline
\end{tabular}

\subsubsection{Food}

Blockchain technology offers the ability to track food products throughout their entire lifecycle and, therefore, increases food supply credibility, efficiency, and safety. The use of IoT sensors and blockchain to track and prevent the entry of illegal foodstuffs into the SC is proposed in [48]. In [49] the authors present FoodSQRBlock (Food Safety Quick Response Block), a blockchain-based framework that digitises food production information and makes it easily accessible, traceable, and verifiable by the consumers and producers through QR codes. Large-scale implementation of FoodSQRBlock in the cloud is also proposed to demonstrate the framework's feasibility and scalability. In [50] the authors propose a food ingredient certification structure based on ERC-20 Ethereum tokens, denoted as IGR tokens in the article. The system can protect sensitive company data for foods derived from commingling processes. Using blockchain technology and Electronic Product Code Information Services (EPCIS), the authors in [51] develop a food safety traceability system. The proposed management architecture of on-chain and off-chain data can alleviate the data processing capabilities of blockchain, reducing the impact of the amount of data generated by IoT devices. In [52] the authors propose the use of blockchain, machine learning, and fuzzy logic to create a food traceability system based on the shelf life management system for handling perishable food. A blockchain IoT-based food traceability system is presented in [53]. The system improves quality assurance and supports shelf life adjustment and quality decay evaluation. Finally, in [54] the authors create a system that eliminates the need for centralisation, intermediaries, and information transfers while also increasing performance and adhering to strict security and integrity standards for food SC traceability.

Several authors proposed food SC traceability solutions for specific products. For example, in [55] the authors develop a blockchain-based traceability system for eggs. Various authors cover meat supply and relevant traceability systems. For instance, in [56] the authors describe a traceability system developed by Australian producers and external stakeholders as a trusted SC solution for the global beef industry. In [57] the authors use advanced deep learning techniques, IoT, and blockchain for developing a food provenance system. The proposed system handles information on meat product traceability. A smart contract-based SC framework for beef traceability is presented in [58]. The authors use a permissioned blockchain network to track business processes across the beef SC.

Other blockchain-based SC traceability approaches cover bread, fish, wheat/flour, grains, and dairy products. For instance, a distributed, trustless, and secure food SC traceability architecture is developed and tested in [59]. A dairy case study is used to test the feasibility of the proposed approach. Developing fully functional smart contracts and a local private blockchain further shows the model's applicability. In [60] the authors describe a decentralised application for developing and implementing a smart contract to ensure that each link in the bread supply chain can independently verify the safety, quality, and suitability of individual batches and products. The system allows the actors to verify that good hygiene practices are followed, essential for maintaining a sanitary environment to meet the Hazard Analysis and Critical Control Point (HACCP) requirements. A food traceability system using Hyperledger is described in [61], in which stakeholders can be linked through food-related transactions. The processing and circulation information 
and the food change process are recorded, leveraging auditable food traceability. The system allows inspection entities to check food quality before uploading traceability-related information on the blockchain. In [62] the authors use IoT devices that communicate directly with Ethereum-based blockchains through a software framework. Rather than relying on a centralised intermediary or third-party services, the proposed solution allows for integrating a wide range of IoT devices. The project's primary use case is in Industry 4.0enabled food chain traceability. A use case for monitoring the temperature of fish products highlights the practicability of the designed system. In [63] the authors, by fusing and integrating IoT and blockchain technology, develop a traceability management solution that aims to improve the easy-perishable aquatic food management during cold chain logistics. Finally, in [64] the authors present a system architecture for the entire grain-based on blockchain technology, as well as a multimode storage mechanism that includes chain storage. In Table 5 we present a comparison of the different features extracted from the food SC literature.

Table 5. Comparison of the different features extracted from the food supply chain literature.

\begin{tabular}{|c|c|c|c|}
\hline Source & Methodology & Product & Sustainability Perspective \\
\hline [48] & $\begin{array}{l}\text { Architecture development, system design/testing, } \\
\text { simulation }\end{array}$ & Agnostic & Social \\
\hline [55] & $\begin{array}{l}\text { Use case, architecture development, system de- } \\
\text { sign/testing }\end{array}$ & Eggs & Social \\
\hline [56] & $\begin{array}{l}\text { Focus groups, use case, architecture development, sys- } \\
\text { tem design/testing }\end{array}$ & Beef & Social, economic \\
\hline [59] & $\begin{array}{l}\text { Case study analysis, architecture development, sys- } \\
\text { tem design/testing }\end{array}$ & Dairy products & Social, economic \\
\hline$[60]$ & Architecture development, system design/testing & Bread & Social, economic \\
\hline [49] & $\begin{array}{l}\text { Architecture development, system design/testing, } \\
\text { performance evaluation }\end{array}$ & Agnostic (from farm-to-fork) & Social \\
\hline$[50]$ & Architecture development, system design/testing & Agnostic & Social, economic \\
\hline [58] & Architecture development, system design/testing & Beef & Social \\
\hline$[61]$ & $\begin{array}{l}\text { Use case scenario, architecture development, system } \\
\text { design/testing, performance analysis }\end{array}$ & Wheat, flour & Social \\
\hline [62] & $\begin{array}{l}\text { Use case scenario, architecture development, system } \\
\text { design/testing, performance analysis }\end{array}$ & Fish and seafood products & Social, economic \\
\hline [57] & $\begin{array}{l}\text { Architecture development, system design/testing, } \\
\text { performance evaluation }\end{array}$ & Meat & Social, economic \\
\hline [51] & $\begin{array}{l}\text { Architecture development, system design/testing, } \\
\text { performance evaluation }\end{array}$ & Agnostic & Social \\
\hline$[54]$ & $\begin{array}{l}\text { Architecture development, system design/testing, } \\
\text { performance analysis }\end{array}$ & Agricultural product & Social, economic \\
\hline [52] & $\begin{array}{l}\text { Case study, architecture development, system de- } \\
\text { sign/testing, performance analysis, security analysis }\end{array}$ & Perishable food products & Social, economic \\
\hline [53] & $\begin{array}{l}\text { Case study analysis, architecture development, sys- } \\
\text { tem design/testing, performance analysis }\end{array}$ & Perishable food products & Social, economic \\
\hline [64] & $\begin{array}{l}\text { Architecture development, system design/testing, } \\
\text { performance analysis, security analysis, comparison } \\
\text { analysis }\end{array}$ & Grains & Social, economic \\
\hline [63] & $\begin{array}{l}\text { Architecture development, system design/testing, } \\
\text { performance analysis }\end{array}$ & Aquatic products & Social, economic \\
\hline
\end{tabular}




\subsubsection{Agriculture/Agri-Food}

While food supply covers processing/production or transforming agricultural products into food, agri-food supply includes some additional processes such as harvest, production, postharvest, etc. Agricultural systems account for the majority of the world's food supply. Therefore, traceability in the agricultural SC is of paramount importance [65]. The authors in [66] design and develop a framework for tracing agri-food products with a specific focus on pepper. In [67] the authors propose a blockchain and edge computingbased information management framework for organic food supply. They implement a blockchain-based data-sharing model that ensures the immutability of traceability records. Edge computing is used to lower the cost of data processing and increase the average response time. The use of blockchain and cloud computing is presented in [68], where the authors propose a method for managing the Colombian agricultural SC. A blockchainbased mechanism called AgriOnBlock is presented in [69]. The mechanism connects various stakeholders using IoT devices and Ethereum smart contracts.

IoT, machine learning, and blockchain technologies are used in the reverse chain of agrochemical products, as seen in [70]. Such an approach also provides legal protection by meeting social needs to protect workers and the environment while preventing product misuse. In [71] the authors present a cost-effective credit system that allows associated farmers to buy high-quality agricultural products. For ensuring optimal grading, the system includes a score-based farm-food quality assurance module. The authors use the Ethereum blockchain and smart contracts for maintaining trust, transparency, and traceability. The different aspects of using blockchain and smart contracts with the integration of IoT devices in the pre-harvesting and post-harvesting segments of agriculture are investigated in [72]. The authors propose a system in which blockchain serves as the backbone, whereas IoT devices collect data at the field level, and smart contracts govern interactions between all stakeholders. A blockchain-based system for tracking soybeans along the agricultural $\mathrm{SC}$ is presented in [73]. The authors use the Ethereum blockchain and smart contracts to control all interactions, transactions and stakeholders within the soybeans SC ecosystem. In [74] the authors present an end-to-end solution for agri-food SC. By using Ethereumbased smart contracts, the suggested approach ensures an efficient and secure SC. To improve transparency and data integrity, the authors in [75] propose a traceability system based on blockchain technology and IoT. The system can improve food traceability and increase public awareness of food safety and quality control. The authors in [76] propose a framework for tracking and tracing agricultural products based on consortium blockchain and smart contracts. Farmers use IPFS to record environmental details and crop growth data and then store IPFS hashes in smart contracts, improving data security and alleviating the blockchain storage explosion problem. A dual storage structure of on-chain and offchain traceability information is described in [77] to alleviate chain load strain and achieve efficient information inquiry. The system improves query efficiency and data security, ensures data validity and dependability in management, and meets real-world application requirements. The authors in [78] present a decentralised NFC-enabled anti-counterfeiting system for facilitating trustworthy data provenance retrieval, verification, and management in the wine industry. In Table 6 we present a comparison of the different features extracted from the agriculture/agri-food SC literature. 
Table 6. Comparison of the different features extracted from the agriculture/agri-food supply chain literature.

\begin{tabular}{|c|c|c|c|}
\hline Source & Methodology & Product & Sustainability Perspective \\
\hline$[66]$ & $\begin{array}{l}\text { Architecture development, system de- } \\
\text { sign/testing }\end{array}$ & Pepper & Undefined \\
\hline [67] & High-level architecture development & $\begin{array}{l}\text { Agnostic (organic agricultural } \\
\text { products) }\end{array}$ & Social, economic \\
\hline [70] & $\begin{array}{l}\text { Architecture development, system de- } \\
\text { sign/testing, performance evaluation }\end{array}$ & Agrochemicals/Pesticides & Social, economic, environmental \\
\hline [68] & $\begin{array}{l}\text { Architecture development, system de- } \\
\text { sign/testing, performance evaluation }\end{array}$ & Agricultural products & Social, economic \\
\hline [69] & $\begin{array}{l}\text { Architecture development, system de- } \\
\text { sign/testing, security analysis, cost analysis }\end{array}$ & Crops & Social, economic \\
\hline [71] & $\begin{array}{l}\text { Architecture development, system de- } \\
\text { sign/testing, performance analysis, compari- } \\
\text { son analysis }\end{array}$ & Agri-food products & Social, economic \\
\hline [72] & $\begin{array}{l}\text { Architecture development, system de- } \\
\text { sign/testing, performance analysis, cost } \\
\text { analysis }\end{array}$ & Agricultural products & Social, economic \\
\hline [73] & Architecture development and implementation & Soyabean & Social \\
\hline [74] & $\begin{array}{l}\text { Architecture development, system de- } \\
\text { sign/testing, performance analysis, security } \\
\text { analysis }\end{array}$ & Agnostic/agri-food products & Social, economic \\
\hline [75] & $\begin{array}{l}\text { Architecture development, system de- } \\
\text { sign/testing }\end{array}$ & Beef (other agricultural products) & Social \\
\hline [76] & $\begin{array}{l}\text { Architecture development, system de- } \\
\text { sign/testing, cost analysis }\end{array}$ & Buckwheat & Social, economic \\
\hline [77] & $\begin{array}{l}\text { Architecture development, system de- } \\
\text { sign/testing, performance analysis }\end{array}$ & Agricultural products & Social \\
\hline [78] & $\begin{array}{l}\text { Architecture development, system de- } \\
\text { sign/testing }\end{array}$ & Wine & Social \\
\hline
\end{tabular}

\subsubsection{Pharmaceuticals}

The pharmaceuticals SC is a particular production-distribution chain that involves an extensive combination of participants and processes. The ability to trace drugs from all stakeholders involved and at any time is critical in the pharmaceuticals SC. In recent years, more and more complex production and distribution channels have been introduced in the pharmaceuticals SC, characterised by various structures and participants. For example, the growing number of online drugstores adds complexity to the logistics structure and increases the intensity of the threat of counterfeit products [79].

Blockchain could be used to improve drug traceability and transparency in a medical SC system. The system stores all of a medicine batch's transfer history and registration and uploads all details on the platform's network. Further exchange of this batch requires both sender and receiver approval, and the exchange transaction is permanently stored on the network. This eliminates the possibility of fraud by a third party [80]. In [81] the authors apply simulation and blockchain technology to test the deployment of traceability processes in the pharmaceutical industry, especially drug traceability. The authors considered the entire pharmaceutical ecosystem, including the pharmaceutical industry, pharmaceutical wholesalers (distributors/wholesalers), health services (drug stores, hospitals), and consumers. Using a five-layer blockchain platform architecture, the authors in [82] develop a blockchain-enabled drug traceability system. They use smart contracts 
and IoT-related applications to manage drug identity and enable on-chain and off-chain mechanisms. Hyperledger Fabric was used to verify the platform's feasibility and efficiency based on real data from participating companies [82]. In [83,84] the authors present a private Ethereum blockchain-based solution for the management of controlled medications. Smart contracts record all actions on the ledger, thus assuring transparency, accountability, security, and data provenance. The authors use IPFS-based off-chain storage to store large-scale content-like images. Another important aspect in the pharmaceuticals SC is the tracking of counterfeit drugs. In [85] the authors demonstrate how blockchain can be used to combat counterfeiting and ensure pharmaceutical traceability. They use blockchain for developing a viable anti-counterfeiting and traceability system for drugs. To test their approach, they create a blockchain environment using Python scripting and run a virtual traceability simulation [85]. In [86] the authors propose a blockchain-enabled system called Medledger using the Hyperledger Fabric blockchain platform. The system enhances the control and interaction among the participating stakeholders in the drug SC ecosystem. For maximum transparency and traceability, the proposed system permanently stores and records all activities, events, and transactions on the blockchain, which is linked to peer-to-peer decentralised file systems like IPFS, Swarm, Filecoin, and others [86]. Finally, to improve the quality of IoT-related data in the context of logistics traceability, the authors in [87] propose a distributed architecture. They apply their approach in a medical equipment use case scenario related to perishable medical diagnostic kits.

Some researchers have developed blockchain-enabled traceability systems for vaccines, apart from drugs and medical equipment. In [88] the authors propose a software solution for the collection and integration of supply-side traceability and consumptionside information in vaccine supply. The proposed system addresses vaccine traceability from regional centres to the end consumer, using cold storage networks and vaccinehandling/administration facilities. In [89] the authors develop a "vaccine blockchain" system that combines blockchain and machine learning technologies. The proposed system makes vaccination traceability and smart contract functions easier and prevents vaccine expiration and record fraud. Machine learning models can also help immunisation practitioners and recipients make better choices when it comes to immunisation techniques and vaccines [89]. In Table 7 we present a comparison of the different features extracted from the pharmaceuticals SC literature.

Table 7. Comparison of the different features extracted from the pharmaceuticals supply chain literature.

\begin{tabular}{|c|c|c|c|}
\hline Source & Methodology & Product & Sustainability Perspective \\
\hline [88] & Architecture development and system design/testing & Vaccines & Social \\
\hline [87] & Architecture development, system design/testing, simulation & Perishable medical diagnostic kits & Undefined \\
\hline [81] & Architecture development, system design/testing, simulation & Drugs & Undefined \\
\hline [82] & $\begin{array}{l}\text { Architecture development, system design/testing, performance } \\
\text { evaluation }\end{array}$ & Drugs & Social, economic \\
\hline [83] & $\begin{array}{l}\text { Architecture development, system design/testing, performance } \\
\text { evaluation }\end{array}$ & Drugs & Social \\
\hline [84] & $\begin{array}{l}\text { Architecture development, system design/testing, performance } \\
\text { evaluation }\end{array}$ & Drugs & Social \\
\hline$[80]$ & $\begin{array}{l}\text { Architecture development, system design/testing, security analysis, } \\
\text { comparison analysis, cost analysis }\end{array}$ & Drugs & Social \\
\hline [79] & Use case scenario, architecture development, system design/testing & Drugs & Social \\
\hline [86] & $\begin{array}{l}\text { Case study analysis, architecture development, system de- } \\
\text { sign/testing }\end{array}$ & Drugs & Social, economic \\
\hline [89] & Architecture development, system design/testing & Vaccines & Social \\
\hline [85] & $\begin{array}{l}\text { Architecture development, system design/testing, performance } \\
\text { analysis, security analysis, comparison analysis }\end{array}$ & Drugs & Social, economic \\
\hline
\end{tabular}




\subsubsection{Manufacturing}

Traceability is of paramount importance in manufacturing. Traceability systems can reduce the size of a recall from millions to just a few hundred units. In addition, in a global marketplace where counterfeiting and recalls are on the rise, modernised manufacturing regulations are more important than ever to improve value chain traceability. In [90] the authors use blockchain technology to prove the authenticity of 3D printed products. They use Ethereum-based smart contracts to regulate and track transactions initiated by participants in the manufacturing process. A blockchain-based solution that secures the traceability of the printing process can be used to prove the authenticity of a 3D printed product. They use IPFS for storing and sharing design files, IoT device records, and other product specifications in a decentralised manner. Decentralised digital manufacturing of medical devices and their supply can be achieved using a blockchain-based solution presented in [91]. The authors describe the system's architecture and algorithms in detail and their implementation and testing. The proposed solution is shown to be cost-effective and resistant to well-known security threats and vulnerabilities. Steel products require information certification to be available to all parties across the SC, including manufacturers, distributors, and end-users. Traditional information traceability processes in the steel industry suffer from a lack of transparency and incomplete data. The authors in [92] use the Hyperledger blockchain platform to create a quality traceability system that safeguards manufacturing-related information in the steel industry. TokenTrail [93] is a decentralised blockchain application that focuses on the unique traceability needs of multi-hierarchical assembly structures. The suggested architecture is built on a consortium Ethereum network using a proof of authority consensus mechanism. The authors created an assembly token manager based on the semi-fungible ERC 1155 token to address the difficulties of managing liaison transformations. The token directly represents complicated assembly processes and structures comprising unique pieces and batches within a single smart contract. In Table 8 we present a comparison of the different features extracted from the manufacturing SC literature.

Table 8. Comparison of the different features extracted from the manufacturing supply chain literature.

\begin{tabular}{clcc}
\hline Source & Methodology & Product & Sustainability Perspective \\
\hline [90] & $\begin{array}{l}\text { Architecture development, system de- } \\
\text { sign/testing, simulation, cost benefit } \\
\text { analysis, security analysis }\end{array}$ & Agnostic & Economic \\
\hline [91] & $\begin{array}{l}\text { Architecture development, system de- } \\
\text { sign/testing, simulation, cost benefit } \\
\text { analysis, security analysis }\end{array}$ & Medical supplies & Economic, environmental \\
\hline [92] & $\begin{array}{l}\text { Architecture development, system de- } \\
\text { sign/testing }\end{array}$ & Steel & Social \\
\hline A93] & $\begin{array}{l}\text { Architecture development, system de- } \\
\text { sign/testing, performance evaluation }\end{array}$ & $\begin{array}{c}\text { Automotive and electrical and } \\
\text { electronic systems }\end{array}$ & Economic \\
\hline
\end{tabular}

\subsubsection{Electronics}

The electronics SC is complex and involves transforming raw materials or natural resources into circuit boards and electronic components, integrating and assembling them into finished goods, and finally making them available to customers. In [94] the authors propose a blockchain-based ownership management system for tracking integrated circuits (IC). The system allows for the verification and recording of IC ownership transfer information and the prevention of any malicious party altering or challenging the legitimacy of the data. A non-destructive method for verifying the traceability of individual electronic parts is presented in [95]. In [96] the authors present a smartphone anti-counterfeiting system based on decentralised identifiers and blockchain technology. The proposed system eliminates the need for a central authority and includes identity creation, ownership 
transfer, and the ability to quickly and securely report stolen devices. An IOTA-based provenance system for product traceability that incorporates the diversified product story as provenance data at each SC intermediate phase is proposed in [97]. The authors address both the problem of product counterfeiting and the problem of fragmented and asymmetric information. They assess and demonstrate that the suggested strategy is acceptable for the electronics SC to connect SC data to the IOTA ledger and create provenance data. They also create a proof-of-concept for the proposed scheme using the Raspberry Pi 3B hardware platform to simulate the IoT-integrated electronics SC and analyse the measured average time and energy consumption for handling provenance data [97]. In Table 9 we present a comparison of the different features extracted from the electronics SC literature.

Table 9. Comparison of the different features extracted from the electronics supply chain literature.

\begin{tabular}{|c|c|c|c|}
\hline Source & Methodology & Product & $\begin{array}{c}\text { Sustainability } \\
\text { Perspective }\end{array}$ \\
\hline [94] & $\begin{array}{l}\text { Architecture development, system de- } \\
\text { sign/testing, performance evaluation, cost } \\
\text { analysis }\end{array}$ & $\begin{array}{l}\text { Electronics (integrated } \\
\text { circuits) }\end{array}$ & Economic \\
\hline [95] & $\begin{array}{l}\text { Architecture development, system de- } \\
\text { sign/testing, performance evaluation, } \\
\text { security analysis }\end{array}$ & $\begin{array}{c}\text { Electronic } \\
\text { parts/devices }\end{array}$ & Economic \\
\hline [96] & $\begin{array}{l}\text { Architecture development, system de- } \\
\text { sign/testing, performance evaluation, cost } \\
\text { analysis }\end{array}$ & Mobile phones & Undefined \\
\hline [97] & $\begin{array}{l}\text { Architecture development, system de- } \\
\text { sign/testing, performance analysis, security } \\
\text { analysis }\end{array}$ & Mobile phones & Social \\
\hline
\end{tabular}

\subsubsection{Miscellaneous}

This subsection presents the remaining papers pertaining to various domains such as apparel, aviation, automobile industry, and construction. A blockchain-based traceability system for the multi-tier textile and clothing is proposed in [98]. The authors use smart contracts to capture the interactions among SC stakeholders and SC processes taking place. Using Hyperledger Fabric and Hyperledger Composer, the authors in [99] propose a management platform for data traceability and information sharing of spare parts in the aviation industry. The platform ensures data integrity and transparency throughout the processes taking place. In [100] the authors use the Hyperledger Fabric to develop an anti-counterfeiting platform in the automobile industry. The platform can be used to prevent counterfeiting in the presence of malicious SC parties while ensuring parties accountability and privacy interests. A novel blockchain-based information management system for a precast SC is presented in [101]. The authors demonstrate the applicability of their system through a case study in which a visualization system is used to achieve information sharing management, real-time scheduling control, and information traceability. In Table 10 we present a comparison of the different features extracted from the miscellaneous SC literature. 
Table 10. Comparison of the different features extracted from the miscellaneous supply chain literature.

\begin{tabular}{clcc}
\hline Source & Methodology & Product & Sustainability Perspective \\
\hline$[98]$ & $\begin{array}{l}\text { Architecture development, system design/testing, simula- } \\
\text { tion }\end{array}$ & Cotton & Social, environmental \\
\hline$[99]$ & $\begin{array}{l}\text { use case scenario, architecture development, system de- } \\
\text { sign/testing, performance analysis }\end{array}$ & Aircraft spare parts & Undefined \\
\hline$[100]$ & $\begin{array}{l}\text { Architecture development, system design/testing, perfor- } \\
\text { mance evaluation, security analysis }\end{array}$ & Airbags & Undefined \\
\hline$[101]$ & $\begin{array}{l}\text { Case study, architecture development, system de- } \\
\text { sign/testing, simulation, cost analysis }\end{array}$ & Precast concrete products & Economic \\
\hline
\end{tabular}

\subsection{Analysis of Implementation Details}

In this section, we analyse the technical contributions of the reviewed literature by identifying the underlying blockchain technology, the maturity of the solution, and the quality of the experiments (i.e., if the study provides a comparison with similar approaches).

The maturity of the implementation was assessed according to the sophistication of the implementations and the technologies used. Test level implementation included the use of automated scripts, command-line interfaces, and basic performance tests using test suite tools such as the popular Truffle suite (https: / / github.com/trufflesuite, accessed on 11 December 2021). More advanced implementations included decentralised digital applications with integrated identity management, richer functionalities, and user interfaces to operate with the smart contract (i.e., DApps with either a Web interface, namely WebApps, or used via mobile devices).

For a blockchain's components to be deemed trustworthy, testers need to verify that they all function correctly and interact with the blockchain in a trustworthy manner. Functional, performance, API, node, and other specialised tests are the most important. As seen in the reviewed literature, most of the works provided performance indicators of their proposals (e.g., executing tests to measure the latency of their transactions to provide scalable solutions and the cost of the different smart contract operations).

Concerning the underlying blockchain technologies used, Ethereum blockchain (https: / / ethereum.org/en/, accessed on 11 December 2021) is the most used due to its rich ecosystem of developer tools and established best practices that have developed as the protocol has matured. Ethereum-ready wallets like MetaMask (https://metamask.io/, accessed on 11 December 2021), Argent (https:/ /www.argent.xyz/, accessed on 11 December 2021), Rainbow (https:/ / rainbow.me/, accessed on 11 December 2021), and others offer simple interfaces for the average user of Ethereum applications to interact with the Ethereum blockchain and smart contracts deployed there. The following preferred technology is Hyperledger, a global enterprise blockchain project. For example, the Hyperledger projects (https://www.hyperledger.org/, accessed on 11 December 2021) include a variety of enterprise-ready permissioned blockchain platforms, where network participants know each other and therefore have an intrinsic interest to participate. Finally, other technologies such as IOTA (https://www.iota.org/, accessed on 11 December 2021), an open-source, public permissionless distributed ledger aiming to become the de facto standard for mobile financial transactions, and Microsoft Azure (https:/ / azure.microsoft.com/en-us/solutions/blockchain/, accessed on 11 December 2021), a discontinued project that has migrated to the ConsenSys's Quorum Blockchain Service (https: / / consensys.net/ quorum/qbs / , accessed on 11 December 2021), are other solutions that have received less attention due to their level of maturity.

As depicted in Figure 4, the majority of the papers provided test-level implementations. In addition to the aforementioned blockchain technologies, we found a small number of ad-hoc implementations using Python, and few cases in which Bigchaindb (https:/ / www. bigchaindb.com/, accessed on 11 December 2021), Multichain (https:/ /www.multichain. 
com/, accessed on 11 December 2021), or OurSQL (http:/ / oursql.org/, accessed on 11 December 2021) were used.

According to our statistics, only 26 out of 72 papers (i.e., approximately $36 \%$ ) included an analysis comparing their methods with state of the art by using metrics and/or a descriptive discussion. This fact is related to the need to use different programming languages and requirements to validate such platforms, which hinders direct comparisons, especially when there are no standardised benchmarks.

Finally, we analysed the challenges related to blockchain technology and the implementations' outcomes provided by such works. Several authors claimed issues related to performance (e.g., latency of transactions, time required to create a block) as the primary concern. The next most discussed challenge was the cost related to the deployment of smart contracts and transactions, which affected public blockchain systems such as Ethereum. The rest of the challenges include implementation issues due to the maturity of the technology and the lack of regulations and standards, which hinders the adoption of such solutions in different industries.

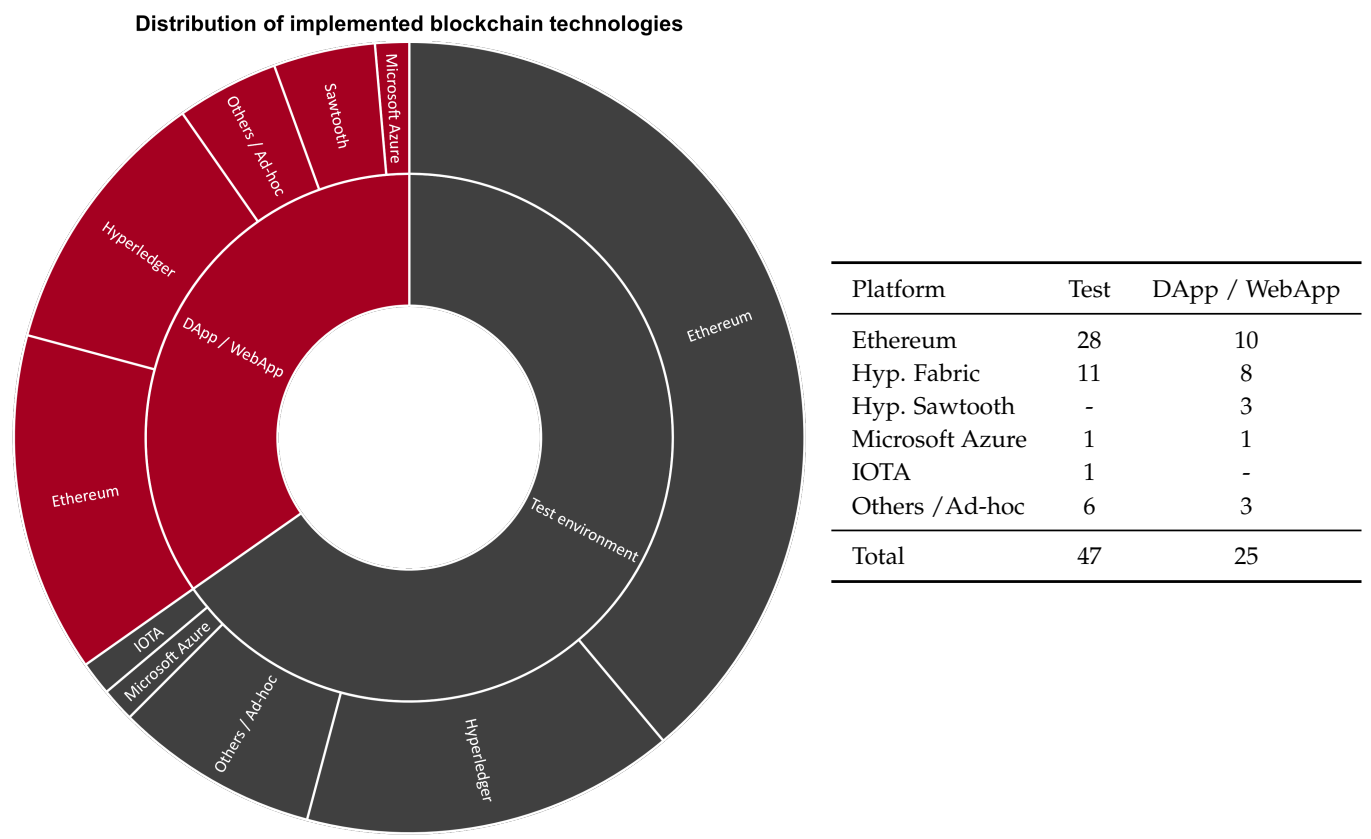

Figure 4. Distribution of the different blockchain technologies used in the reviewed literature. The others and ad-hoc category includes less popular technologies such as Bigchaindb, Multichain, and OurSQL, which were used two or fewer times.

\section{Discussion}

Based on the analysis described in Section 4, in what follows, we provide key takeaways regarding the open issues and challenges of current blockchain-enabled SC traceability implementations, along with fruitful areas for future research. In addition, we summarise the key findings of our research concerning the research questions initially posed. Finally, we discuss some limitations that our research presents.

\subsection{Open Issues and Challenges}

Despite the numerous advantages of blockchain technology for establishing sound traceability systems, specific challenges remain. This section provides a classification of the main challenges and open issues relevant to blockchain technology and its broader usage in SC traceability solutions.

Real life testing pilots: Several organizations are currently involved in real-world pilot studies for adopting blockchain in SC traceability. As far as these pilot initiatives are concerned, they exhibit the potential of blockchain traceability solutions. Still, they are not 
sufficient to prove the capabilities of blockchain to deliver real business value. Despite significant investments in blockchain, little is said about the technology's full deployment. Most blockchain services are available on a limited-revenue basis and are managed at a pilot scale, usually within corporate boundaries. We believe that any architecture evaluation should be tested in a real-life scenario to ensure its performance in the context of SC traceability, taking into account different cost pools and operational requirements.

There is also a high barrier to technology and process adoption regarding real-life testing solutions. The integration of traceability technologies (including different devices) and processes, which do not exist in all SC networks, pose a significant barrier, especially in less technology-intensive SC industries. Blockchain is still in its infancy, and its penetration is limited in many sectors. Therefore, the technology's lack of awareness and understanding may prevent certain SC participants from accepting blockchain-based SC traceability solutions. Implementing larger distributed systems will also prove difficult as system size and complexity must increase. Complex operational processes and interest-conflicting participants exist in real life SC scenarios. Therefore, the practicability and feasibility of blockchain-based traceability solutions should be verified across all SC participants taking into account end-to-end approaches.

Under the real application of blockchain solutions, the user feedback (i.e., involving all SC actors, both upstream and downstream of the SC) must be thoroughly collected and assessed. User input can be used for fine-tuning and optimizing the blockchain-based traceability workflow. In addition, designing and deploying information management systems across an entire SC is complex and costly. Incremental modification and augmentation to existing systems could provide a practical and cost-effective pathway to utilise blockchain technologies with legacy systems.

Evaluation and benchmarks: As observed in the literature, there is a lack of standardised benchmarks to compare different blockchain implementations, especially in light of different hardware, software setups, and transaction types. Most studies provide experimental results of the performance and scalability of their solutions in terms of transactions per second and the approximate cost in terms of gas fees. However, few papers provide a security analysis of their implementations, including the smart contract code. We believe that standardised cross-platform benchmarks are necessary so that authors discuss the real value of their works in practical scenarios and provide sound advancements in the state of the art. Moreover, real case studies are also necessary to understand the suitability of the different blockchain technologies/platforms according to the application context while measuring long term performance, managerial aspects, privacy and security, and other measurable features. For instance, according to latency and cost fees, novel public platforms such as Solana, Polkadot, Cardano, as well as Layer 2 solutions such as the Lightning Network (https:/ /lightning.network/, accessed on 15 December 2021), may fulfill the requirements for sustainable blockchain-based systems in the short to mid-term, but presently are unfeasible with, e.g., Ethereum due to increased gas fees.

Sustainability concerns: During our analysis, it was not easy to identify how blockchainbased traceability solutions bring economic, environmental, and social value. The sustainability perspective was always implied/inferred in all selected papers and not explicitly stated. For example, although some authors note significant benefits of the technology concerning the social dimension of sustainability, it is not clear how a company/sector can meet the expectations of various stakeholders concerning societal priorities (including its customers). The same holds for the economic dimension of sustainability, where real-life testing is needed for assessing the potential of blockchain technology to bring down operational costs and increase the overall SC surplus. This is particularly true because all the papers' cost dimensions were concerned with blockchain-related costs (for example, gas fees, etc.) and not the SC economic benefits from adopting the blockchain technology in SC traceability. Future research is needed for uncovering how the technology can bring value in terms of increased environmental performance. Environmental-related concerns are 
significant, especially if we consider the massive energy requirements of current blockchain networks.

Organizational challenges: Various exploratory studies report on significant barriers to blockchain adoption in an organizational context, such as lack of specialised personnel, low organizational readiness and organizational culture [102], and "resistance to change" attitude [103]. Some SC participants may have difficulties addressing the technological uncertainties around blockchain, especially because they lack good organisational capabilities and a company culture receptive to new technologies. The wider adoption of blockchain across SC participants requires expertise, which is difficult for small and medium-size organisations to possess. In addition, small and medium-size organisations may be unaware of blockchain technology or may not have the necessary personnel to embrace the technology. Moreover, big SC players may have insufficient training capacities for educating non-specialised people. In general, open business culture and severe organisational transformation must adopt blockchain technology across SC participants.

Investment and operational costs: Building blockchain applications entails high costs. The cost to build blockchain-enabled solutions depends on various factors such as the project's complexity, blockchain technology suitability analysis, and other technology and operational stacks. Blockchain implementation incurs various design, development, deployment, migration, and maintenance costs. For example, significant initial investment costs are incurred at the initial application stage, and the reuse of an existing blockchain network may be difficult due to the one-off characteristic of construction projects. There is a cost incurred for smart contract deployment, function calls in the smart contract, and each transaction initiated by the smart contract. These cost items could result in high operational costs if the contract is not programmed to keep cost-effectiveness in mind. Other costs include coding and testing, deployment on cloud platforms, moving the existing solution to the blockchain platform, maintaining new updates and testing that the app runs smoothly on every OS release, and third party costs (hosting, storage). Blockchain platforms also contribute to the cost of blockchain app development. A developer has to pay a certain fee to deploy a contract on the blockchain. Note that not all collaboration models in SC are based on a win-win philosophy. The prevalence of internal-only traceability systems across SC networks unavoidably gives rise to opportunistic behaviour. Experience has shown that the processing firms (upstream SC members) may bear the financial burden of implementing traceability. At the same time, gains are reaped by firms in the distribution businesses closer to the end customer (downstream SC members) [104]. SC participants aspiring to adopt blockchain applications should view the benefits from a long-term perspective. Future work should evaluate the entire realization cost of the system, taking into account the system as a whole and under reasonable time frames.

Integrating blockchain with existing enterprise resource planning (ERP) systems necessitates substantial financial commitment. In general, updating business information systems and incorporating cutting-edge technology into a company's arsenal necessitates significant long-term financial investments. On-boarding and maintenance expenses are also significant. Suppliers, third-party logistics providers, distributors, and manufacturers who participate in a SC network will be responsible for the cost of hosting a node (energy spent) inside a blockchain consortium. High costs will be incurred in the form of maintenance, data storage, and infrastructure improvements as a result of high volume transactions over broad SC networks, and SC members will be responsible for these expenses [103].

Blockchain-related technological challenges: Despite being received as a panacea by many practitioners, the truth is that blockchain has several challenges that require further efforts to overcome. Concerning performance, aspects such as transaction latency, which affects scalability [17,105], are essential to ensure proper functioning of the blockchain solutions. Note that in the concrete scenario of ERP-related technologies and apps (gateways for the connection to the blockchain, diversity of protocols, standards, volume, and expected throughput, etc.), scalability may prove to be a big challenge for ERP/blockchain 
integration, given the massive quantity of transactions in current SC networks. The first step to maximise the performance of any SC traceability solution is to leverage a suitability assessment [17]. Selecting the proper blockchain architecture (e.g., public blockchain, private blockchain, and their permission management) is crucial. However, it may condition several functional aspects, and thus, it needs to be performed carefully.

In addition to the blockchain platforms, development aspects are also critical. For example, the development and deployment of efficient and secure smart contracts [106,107], data management procedures (e.g., the use of hybrid approaches that enable decentralised storage to minimise on-chain data storage), and novel approaches that use Layer 2 blockchain solutions [108] remain a challenge. Moreover, by minimising the number of transactions and data stored in the blockchain, we limit the impact of immutability when not desirable or illegal data is at stake [109], as the information stored on the blockchain and decentralised storage systems such as IPFS cannot be easily deleted [110,111]. Finally, blockchain privacy and security issues should also be taken into account [112].

Apart from scalability, lack of standardisation and interoperability frameworks could be significant barriers to successfully integrating ERP systems and blockchain-enabled applications, especially given the numerous ERP solutions on the market and the various blockchain architecture configurations and variants. ERP interactions, for example, are increasingly based on common data formats among SC trade partners. Unfortunately, although being organised, data created by blockchain-enabled apps are not fully covered by standardised frameworks [105]. As a result, data translation between ERP software and blockchain platforms will be required in the coming years. Finally, interoperability across multiple blockchain networks is still a significant difficulty, but it is becoming an essential component of Web3. Interoperability across blockchain networks is essential because it allows data and value to be exchanged smoothly. In SC networks, where SC partners may be members of multiple blockchain networks, such communication is crucial [113].

Addressing the "garbage in, garbage out" challenge: Like all computing systems, output quality is determined by the quality of input in any given blockchain application. Blockchain networks cannot guarantee the veracity of data that was not natively generated on-chain (for example, information coming from sources such as IoT devices across the SC). Apart from devices, humans may also input fraudulent data into the blockchain. For example, workers in the SC may create fake or incorrect data regarding traceability records, and unfortunately, blockchain is unable to detect intentionally and/or unintentionally corrupted data [114]. In this case, and due to the immutability of blockchain technology, SC participants will end up with fraudulent data permanently written to the blockchain. The usage of solid identity management frameworks might be part of the solution, especially self-sovereign identity schemes; however, the veracity of traceability-related records is still undermined by human error. Therefore, future research should focus on the veracity and integrity of traceability-related data and especially on innovative ways to secure the source of generated information across vast SC networks.

Regulatory challenges of blockchain: Blockchain technology's regulatory and legal approval is a cross-sectoral impediment to its broad deployment. The lack of a worldwide legislative framework, in particular, creates barriers to the global acceptance and use of blockchain technology. Data security, cyber-attacks, privacy compliance, and cross-border cooperation are emerging blockchain integration challenges. The difficulties surrounding smart contracts, such as usage, deployment, and enforcement, are significant. It is worth emphasising that the existing legal frameworks for recognising smart contracts worldwide are still in their infancy. It is uncertain if existing law schemes fully protect smart contracts. Because various parties (SC trade partners, government authorities, etc.) are engaged, ERP and blockchain integration poses major regulatory issues. Some regulations should be made on the governmental level to allow this technology in the food sector. Despite initial efforts toward standardisation of blockchain technology (e.g., ISO/TC 307 (https: / / www.iso.org/committee/6266604.html, accessed on 15 December 2021), there is a long 
road ahead considering that legal constraints are also involved in the implementation of such a system.

Blockchain governance: Blockchain governance seems to be the biggest single challenge for the growth of distributed ledgers [115]. Blockchain governance refers to the way disparate stakeholders within the same blockchain project achieve coordination, direction, and control [116]. Not only does blockchain governance necessitate consensus among validating nodes, but it also necessitates consensus among network users. It should be noted that governance on the blockchain is fundamentally different from traditional contractual and relational governance [117]. Practically, the debate over governance in the context of blockchain networks currently revolves around two pillars: centralised vs. decentralised and on-chain vs. off-chain. For example, public blockchain platforms like Ethereum are governed on a distributed basis in line with their autonomous and decentralised operation, leading to issues due to the lack of a central legal entity with formal responsibility for the system. During times of crisis, the risks of such a governance scheme can be amplified as the system's developers try to agree on software code changes to address the problem [115]. Off-chain governance mechanisms include public discussion and collectively agreed-upon updates. In contrast, on-chain governance mechanisms entail online voting (stakeholders vote using tokens to accept or reject a proposed change).

Standardisation and certification of the SC traceability process: SC traceability may greatly benefit when SC actors adopt shared standards for specific practices and methods. However, traceability is based on strong connections between different SC partners, which perform processes that affect the ownership, physical movement, position, or condition of traceable units (external traceability events). Traceability also relies upon appropriate tools for harvesting and managing the internal and external traceability events captured by technologies such as barcodes and RFID tags along with the SC. According to recent studies, the establishment of any traceability framework necessitates a well-organised and standardised framework involving all (internal and external) actors [118]. Both external and internal traceability events will be handled with the EPCIS standard developed by GS1. For example, the GS1 Global Traceability Standard establishes a minimum set of traceability requirements for business processes to achieve full chain traceability regardless of technology. It lays out a common framework for creating a traceability system incorporating other GS1 standards like barcodes, data carriers, eCom, and EPCIS. Standardisation may apply not only to SC operations but also to traceability-related data and events handling. Note also that standardising internal and external traceability processes may require organisational changes. Uniform data definitions and authorities for creating, accessing, and changing data should be ensured by data governance. Data governance cannot be defined solely by the partners of a single blockchain initiative; it necessitates sector, if not industry-wide, agreement. Otherwise, suppliers will be required to adhere to various interface standards, rendering blockchain technology inefficient from an economic standpoint [118].

\subsection{Key Findings}

In what follows, we provide a summary of the main findings of our study in accordance with the various research questions initially posed.

RQ1: The available blockchain-enabled SC traceability implementations encompass various SC domains, such as generic, food, agriculture/agri-food, pharmaceuticals, manufacturing, electronics, apparel, aviation, automobile, industry, and construction. However, most retrieved blockchain implementations fall within the agricultural and food supply domain. These two sectors are of paramount importance in terms of increased visibility, transparency, and security and have attracted most of the attention from the scientific community. Other domains, like pharmaceuticals, have also received considerable attention during recent years. The list of traceable products includes, among others, agricultural products (crops, soybeans, buckwheat, wine, grains, wheat, flour, cotton, etc.), food (eggs, beef, dairy products, fish and seafood, bread, etc.), medical supplies (vaccines, drugs), electronics (electronic parts/devices, e-products, integrated circuits, mobile phones, etc.), 
and other products (steel, aircraft spare parts, airbags, precast concrete products, wind turbine blades, and automotive parts). All authors adopted architecture development and system design/testing methods concerning the methodologies applied. In addition, many authors used simulation as their main testing methodology. Finally, for many authors, cost-benefit analysis was applied as security analysis (mostly informal security analysis). Given the analysed literature, no specific differences were found topic-wise; thus, the maturity of blockchain implementations is a global challenge to overcome, paired with the integration, adoption, and benchmark-related challenges discussed in Section 5.1.

RQ2: As previously discussed in Section 4.2, most implementations do not include advanced and functional interfaces. The latter, paired with the lack of benchmarks and thorough testing under real conditions through use case scenarios, increases the difficulty of assessing the quality of proposed solutions. Concerning the underlying blockchain technologies used, Ethereum blockchain is the most used, followed by Hyperledger. Due to its design and industry-oriented functionality, Hyperldeger implementations presented more maturity on average than the rest of the technologies. Nevertheless, novel blockchain technologies (e.g., Layer 2 solutions as well as blockchain networks with more scalable consensus mechanisms such as Cardano (https:/ / cardano.org/, accessed on 15 December 2021), Polkadot (https:/ / polkadot.network/, accessed on 15 December 2021), or Solana (https:/ / solana.com/, accessed on 15 December 2021), are emerging, which may change the paradigm in the years to come. In this regard, a strategy that enables cross-chain integration and testing is a desirable feature to consider.

$R Q 3:$ The challenges surrounding blockchain regarding its adoption and regulation, and the inherent technological issues, pose a serious overhead. Current literature lacks a systematic way to evaluate the sustainability perspective of their solutions, as authors mainly focus on the performance of the technology. Thus, a de facto evaluation and discussion of the different sustainability aspects is necessary. This is a crucial step for the advancement of the state of the art since it will: (1) improve benchmarking, (2) identify the pain points of this research field, and (3) provide a fruitful ground for discussion towards the rest of blockchain-related challenges discussed in Section 5.1.

RQ4: Enhancing the maturity of implementations and the quality of their evaluations is a complex task. From a comparison-wise perspective, each problem may require different blockchain platforms to be solved, which hinders direct comparisons in the literature. In terms of maturity, many platforms offer ready-to-use attractive solutions for most developers; thus, they are leveraged for research articles to prove functionality. However, these experiments are not enough to provide a holistic view of how a system would perform in real-life SC scenarios. Lack of regulations, standards, and a clear roadmap of "how-to" impede researchers and practitioners from developing and testing sound blockchain-based solutions. Therefore, we believe that all these aspects need to evolve together in parallel, offering a solid paradigm for the transition and adoption of blockchain.

\subsection{Limitations}

We adopted a systematic approach throughout this survey for assessing the retrieved literature. However, our overall approach presents some limitations worth noting. For instance, we may not have achieved content saturation during our search process, especially because we included in our analysis mainly papers published in peer-reviewed journals. Excluding papers published in book chapters or peer-reviewed international conferences may have lessened our survey's comprehensive and interdisciplinary nature. In addition, we believe that papers published in peer-reviewed journals are more likely to be subject to scrutiny from other experts in the same field and to present more sound implementation details than papers published in conference proceedings.

Some process-oriented and theoretical issues relevant to content analysis should also be noted. For instance, content analysis is overly reductive and leads to increased abstraction, aspects that make it challenging to demonstrate that an analysis is credible and trustworthy [119]. Moreover, relational analysis extensively used during the content 
analysis process involves a certain level of subjective interpretation, which may also affect the reliability and validity of the overall analysis. In our case, we have tried to overcome these limitations, especially subjectivity and bias, by applying group discussions where all authors agreed upon the final set of coding themes.

\section{Conclusions}

Customers, SC partners, and other stakeholders increasingly demand greater access to information about a company's multi-tier SC. Regulatory due diligence requirements increased expectations from investors and consumers, and technological advancements have raised the stakes. In this paper, we have presented a systematic literature review of the available blockchain-enabled SC traceability implementations. Based on a sound classification scheme, we have provided a taxonomy of the various blockchain-related SC traceability systems across different domains, with a specific focus on their sustainability features covered. We have also paid particular attention to the maturity and technical features of the available SC traceability implementations, especially in terms of blockchain platforms used and their implementation status.

SC traceability implementations based on blockchain seem to be very popular across various SC domains; however, agricultural and food supply account for most of the selected literature. Concerning the sustainability perspective, most of the selected literature fails to identify specific economic, environmental, and social objectives fulfilled by the proposed blockchain-related SC traceability solutions. According to our analysis, most papers provide test-level implementations using relevant test suites, mainly the Ethereum and Hyperledger (Fabric, Sawtooth) blockchain platforms. The fragmentation of the retrieved literature's performance metrics is another interesting conclusion drawn. It seems that the breadth of the available technical solutions and their underlying technical features hinder direct comparisons, especially when there are no standardised benchmarks. Although blockchain is considered a first-line SC traceability technology, several technical, organisational, and regulatory issues remain unaddressed, such as the scalability of the available platforms, interoperability challenges, throughput, integration with legacy ERP systems, and blockchain-associated legal issues. Altogether, our analysis highlights that research efforts so far have focused on unstructured experimentation of blockchain-related SC traceability solutions. Therefore, there is a clear need to develop and test real-life traceability solutions, especially considering their feasibility to create added value subject to SC cost-related aspects.

Author Contributions: Conceptualization, T.K.D., T.G.V. and G.T.T.; methodology, T.K.D., T.G.V., G.T.T. and F.C.; validation, T.K.D. and F.C.; formal analysis, T.K.D.; investigation, T.K.D., T.G.V., G.T.T. and F.C.; resources, T.K.D. and F.C.; writing-original draft preparation, T.K.D., T.G.V., G.T.T. and F.C.; writing-review and editing, T.K.D. and F.C.; supervision, T.K.D. and G.T.T.; funding acquisition, T.K.D. and F.C. All authors have read and agreed to the published version of the manuscript.

Funding: This research received funding from the Hellenic Open University. F. Casino was supported by the Beatriu de Pinós programme of the Government of Catalonia (Grant No. 2020 BP 00035).

Institutional Review Board Statement: Not applicable.

Informed Consent Statement: Not applicable.

Data Availability Statement: Not applicable.

Conflicts of Interest: The authors declare no conflict of interest.

\section{References}

1. Wang, H.; Pan, C.; Wang, Q.; Zhou, P. Assessing sustainability performance of global supply chains: An input-output modeling approach. Eur. J. Oper. Res. 2020, 285, 393-404. [CrossRef]

2. Reklitis, P.; Sakas, D.P.; Trivellas, P.; Tsoulfas, G.T. Performance Implications of Aligning Supply Chain Practices with Competitive Advantage: Empirical Evidence from the Agri-Food Sector. Sustainability 2021, 13, 8734. [CrossRef] 
3. Laforet, L.; Bilek, G. Blockchain: An inter-organisational innovation likely to transform supply chain. Supply Chain Forum 2021, 22, 240-249. [CrossRef]

4. Akın Ateş, M.; Suurmond, R.; Luzzini, D.; Krause, D. Order from chaos: A meta-analysis of supply chain complexity and firm performance. J. Supply Chain. Manag. 2022, 58, 3-30. [CrossRef]

5. Liu, P.; Hendalianpour, A.; Hamzehlou, M.; Feylizadeh, M.; Razmi, J. Identify and rank the challenges of implementing sustainable supply chain blockchain technology using the bayesian best worst method. Technol. Econ. Dev. Econ. 2021, 27, 656-680. [CrossRef]

6. Azzi, R.; Chamoun, R.; Sokhn, M. The power of a blockchain-based supply chain. Comput. Ind. Eng. 2019, 135, 582-592. [CrossRef]

7. Katsikouli, P.; Wilde, A.; Dragoni, N.; Høgh-Jensen, H. On the benefits and challenges of blockchains for managing food supply chains. J. Sci. Food Agric. 2021, 101, 2175-2181. [CrossRef]

8. Nguyen, N.B.T.; Lin, G.H.; Dang, T.T. Fuzzy Multi-Criteria Decision-Making Approach for Online Food Delivery (OFD) Companies Evaluation and Selection: A Case Study in Vietnam. Processes 2021, 9, 1274. [CrossRef]

9. Dasaklis, T.K.; Casino, F.; Patsakis, C.; Douligeris, C. A Framework for Supply Chain Traceability Based on Blockchain Tokens. In Business Process Management Workshops; Di Francescomarino, C., Dijkman, R., Zdun, U., Eds.; Springer Nature: Cham, Switzerland, 2019; pp. 704-716.

10. Dasaklis, T.K.; Casino, F.; Patsakis, C. Defining Granularity Levels for Supply Chain Traceability Based on IoT and Blockchain. In Proceedings of the International Conference on Omni-Layer Intelligent Systems, Crete, Greece, 5-7 May 2019 ; pp. 184-190. [CrossRef]

11. Deng, W.; Feng, L.; Zhao, X.; Lou, Y. Effects of supply chain competition on firms' product sustainability strategy. J. Clean. Prod. 2020, 275, 124061. [CrossRef]

12. Arora, A.; Arora, A.; Anyu, J.; McIntyre, J.R. Global Value Chains' Disaggregation through Supply Chain Collaboration, Market Turbulence, and Performance Outcomes. Sustainability 2021, 13, 4151. [CrossRef]

13. Kabadurmus, O.; Erdogan, M. Sustainable, multimodal and reliable supply chain design. Ann. Oper. Res. 2020, 292, 47-70. [CrossRef]

14. Hastig, G.M.; Sodhi, M.S. Blockchain for Supply Chain Traceability: Business Requirements and Critical Success Factors. Prod. Oper. Manag. 2020, 29, 935-954. [CrossRef]

15. Galvez, J.F.; Mejuto, J.C.; Simal-Gandara, J. Future challenges on the use of blockchain for food traceability analysis. TrAC Trends Anal. Chem. 2018, 107, 222-232. [CrossRef]

16. Feng, H.; Wang, X.; Duan, Y.; Zhang, J.; Zhang, X. Applying blockchain technology to improve agri-food traceability: A review of development methods, benefits and challenges. J. Clean. Prod. 2020, 260, 121031. [CrossRef]

17. Casino, F.; Dasaklis, T.K.; Patsakis, C. A systematic literature review of blockchain-based applications: Current status, classification and open issues. Telemat. Inform. 2019, 36, 55-81. [CrossRef]

18. Lashkari, B.; Musilek, P. A Comprehensive Review of Blockchain Consensus Mechanisms. IEEE Access 2021, 9, 43620-43652. [CrossRef]

19. Hewa, T.M.; Hu, Y.; Liyanage, M.; Kanhare, S.S.; Ylianttila, M. Survey on Blockchain-Based Smart Contracts: Technical Aspects and Future Research. IEEE Access 2021, 9, 87643-87662. [CrossRef]

20. Demestichas, K.; Peppes, N.; Alexakis, T.; Adamopoulou, E. Blockchain in agriculture traceability systems: A review. Appl. Sci. 2020, 10, 4113. [CrossRef]

21. Cartier, L.E.; Ali, S.H.; Krzemnicki, M.S. Blockchain, chain of custody and trace elements: An overview of tracking and traceability opportunities in the gem industry. J. Gemmol. 2018, 36, 212-227. [CrossRef]

22. Tharatipyakul, A.; Pongnumkul, S. User Interface of Blockchain-Based Agri-Food Traceability Applications: A Review. IEEE Access 2021, 9, 82909-82929. [CrossRef]

23. Lin, W.; Huang, X.; Fang, H.; Wang, V.; Hua, Y.; Wang, J.; Yin, H.; Yi, D.; Yau, L. Blockchain Technology in Current Agricultural Systems: From Techniques to Applications. IEEE Access 2020, 8, 143920-143937. [CrossRef]

24. Denyer, D.; Tranfield, D. Producing a systematic review. In The Sage Handbook of Organizational Research Methods; Sage Publications Ltd.: Washington, DC, USA, 2009; pp. 671-689.

25. Tranfield, D.; Denyer, D.; Smart, P. Towards a Methodology for Developing Evidence-Informed Management Knowledge by Means of Systematic Review. Br. J. Manag. 2003, 14, 207-222. [CrossRef]

26. Downe-Wamboldt, B. Content analysis: Method, applications, and issues. Health Care Women Int. 1992, 13, 313-321. [CrossRef] [PubMed]

27. Elo, S.; Kyngäs, H. The qualitative content analysis process. J. Adv. Nurs. 2008, 62, 107-115. [CrossRef]

28. Denyer, D.; Tranfield, D. Using qualitative research synthesis to build an actionable knowledge base. Manag. Decis. 2006, 44, 213-227. [CrossRef]

29. Ding, Q.; Gao, S.; Zhu, J.; Yuan, C. Permissioned Blockchain-Based Double-Layer Framework for Product Traceability System. IEEE Access 2020, 8, 6209-6225. [CrossRef]

30. Fernández-Caramés, T.M.; Blanco-Novoa, O.; Froiz-Míguez, I.; Fraga-Lamas, P. Towards an Autonomous Industry 4.0 Warehouse: A UAV and Blockchain-Based System for Inventory and Traceability Applications in Big Data-Driven Supply Chain Management. Sensors 2019, 19, 2394. [CrossRef] 
31. Figorilli, S.; Antonucci, F.; Costa, C.; Pallottino, F.; Raso, L.; Castiglione, M.; Pinci, E.; Del Vecchio, D.; Colle, G.; Proto, A.R.; et al. A blockchain implementation prototype for the electronic open source traceability of wood along the whole supply chain. Sensors 2018, 18, 3133. [CrossRef]

32. Kim, H.M.; Laskowski, M. Toward an ontology-driven blockchain design for supply-chain provenance. Intell. Syst. Accounting, Financ. Manag. 2018, 25, 18-27. [CrossRef]

33. Kumar, G.; Saha, R.; Buchanan, W.J.; Geetha, G.; Thomas, R.; Rai, M.K.; Kim, T.H.; Alazab, M. Decentralized accessibility of e-commerce products through blockchain technology. Sustain. Cities Soc. 2020, 62, 102361. [CrossRef]

34. Latif, R.M.A.; Farhan, M.; Rizwan, O.; Hussain, M.; Jabbar, S.; Khalid, S. Retail level Blockchain transformation for product supply chain using truffle development platform. Clust. Comput. 2021, 24, 1-16. [CrossRef]

35. Sund, T.; Lööf, C.; Nadjm-Tehrani, S.; Asplund, M. Blockchain-based event processing in supply chains-A case study at IKEA. Robot. Comput.-Integr. Manuf. 2020, 65. [CrossRef]

36. Wang, S.; Li, D.; Zhang, Y.; Chen, J. Smart contract-based product traceability system in the supply chain scenario. IEEE Access 2019, 7, 115122-115133. [CrossRef]

37. Westerkamp, M.; Victor, F.; Küpper, A. Tracing manufacturing processes using blockchain-based token compositions. Digit. Commun. Netw. 2020, 6, 167-176. [CrossRef]

38. Yu, H.; Zhu, S.; Yang, J. The quality control system of green composite wind turbine blade supply chain based on blockchain technology. Sustainability 2021, 13, 8331. [CrossRef]

39. Lee, C.H.; Yang, H.C.; Wei, Y.C.; Hsu, W.K. Enabling blockchain based scm systems with a real time event monitoring function for preemptive risk management. Appl. Sci. 2021, 11, 4811. [CrossRef]

40. Mukhtar, A.; Romli, A.; Mohd, N.K. Blockchain network model to improve supply chain visibility based on smart contract. Int. J. Adv. Comput. Sci. Appl. 2020, 11, 76-82. [CrossRef]

41. Li, J.; Song, Y. Design of supply chain system based on blockchain technology. Appl. Sci. 2021, 11, 9744. [CrossRef]

42. Liu, L.J.; Li, C. Research on supply chain architecture of logistics network platform based on blockchain technology. Int. J. Circuits, Syst. Signal Process. 2020, 14, 526-532. [CrossRef]

43. Lou, M.; Dong, X.; Cao, Z.; Shen, J. SESCF: A Secure and Efficient Supply Chain Framework via Blockchain-Based Smart Contracts. Secur. Commun. Netw. 2021, 2021, 8884478. [CrossRef]

44. Omar, I.A.; Jayaraman, R.; Salah, K.; Debe, M.; Omar, M. Enhancing vendor managed inventory supply chain operations using blockchain smart contracts. IEEE Access 2020, 8, 182704-182719. [CrossRef]

45. Ahmad, R.W.; Salah, K.; Jayaraman, R.; Yaqoob, I.; Omar, M.; Ellahham, S. Blockchain-Based Forward Supply Chain and Waste Management for COVID-19 Medical Equipment and Supplies. IEEE Access 2021, 9, 44905-44927. [CrossRef]

46. Oropallo, E.; Secundo, G.; Vecchio, P.D.; Centobelli, P.; Cerchione, R. Blockchain technology for bridging trust, traceability and transparency in circular supply chain. Inf. Manag. 2021, in press. [CrossRef]

47. Sahoo, S.; Mukherjee, A.; Halder, R. A unified blockchain-based platform for global e-waste management. Int. J. Web Inf. Syst. 2021, 17, 449-479. [CrossRef]

48. Balamurugan, S.; Ayyasamy, A.; Joseph, K.S. IoT-Blockchain driven traceability techniques for improved safety measures in food supply chain. Int. J. Inf. Technol. 2021, 1-12. [CrossRef]

49. Dey, S.; Saha, S.; Singh, A.K.; McDonald-Maier, K. FoodSQRBlock: Digitizing food production and the supply chain with blockchain and QR code in the cloud. Sustainability 2021, 13, 3486. [CrossRef]

50. Dos Santos, R.B.; Torrisi, N.M.; Yamada, E.R.K.; Pantoni, R.P. IGR token-raw material and ingredient certification of recipe based foods using smart contracts. Informatics 2019, 6, 11. [CrossRef]

51. Lin, Q.; Wang, H.; Pei, X.; Wang, J. Food Safety Traceability System Based on Blockchain and EPCIS. IEEE Access 2019, 7, 20698-20707. [CrossRef]

52. Shahbazi, Z.; Byun, Y.C. A procedure for tracing supply chains for perishable food based on blockchain, machine learning and fuzzy logic. Electronics 2021, 10, 41. [CrossRef]

53. Tsang, Y.P.; Choy, K.L.; Wu, C.H.; Ho, G.T.S.; Lam, H.Y. Blockchain-Driven IoT for Food Traceability with an Integrated Consensus Mechanism. IEEE Access 2019, 7, 129000-129017. [CrossRef]

54. Prashar, D.; Jha, N.; Jha, S.; Lee, Y.; Joshi, G.P. Blockchain-based traceability and visibility for agricultural products: A decentralizedway of ensuring food safety in India. Sustainability 2020, 12, 3497. [CrossRef]

55. Bumblauskas, D.; Mann, A.; Dugan, B.; Rittmer, J. A blockchain use case in food distribution: Do you know where your food has been? Int. J. Inf. Manag. 2020, 52, 102008. [CrossRef]

56. Cao, S.; Powell, W.; Foth, M.; Natanelov, V.; Miller, T.; Dulleck, U. Strengthening consumer trust in beef supply chain traceability with a blockchain-based human-machine reconcile mechanism. Comput. Electron. Agric. 2021, 180, 105886. [CrossRef]

57. Khan, P.W.; Byun, Y.C.; Park, N. IoT-blockchain enabled optimized provenance system for food industry 4.0 using advanced deep learning. Sensors 2020, 20, 2990. [CrossRef] [PubMed]

58. Ferdousi, T.; Gruenbacher, D.; Scoglio, C.M. A Permissioned Distributed Ledger for the US Beef Cattle Supply Chain. IEEE Access 2020, 8, 154833-154847. [CrossRef]

59. Casino, F.; Kanakaris, V.; Dasaklis, T.K.; Moschuris, S.; Stachtiaris, S.; Pagoni, M.; Rachaniotis, N.P. Blockchain-based food supply chain traceability: A case study in the dairy sector. Int. J. Prod. Res. 2021, 59, 5758-5770. [CrossRef] 
60. Cocco, L.; Mannaro, K.; Tonelli, R.; Mariani, L.; Lodi, M.B.; Melis, A.; Simone, M.; Fanti, A. A Blockchain-Based Traceability System in Agri-Food SME: Case Study of a Traditional Bakery. IEEE Access 2021, 9, 62899-62915. [CrossRef]

61. Gao, K.; Liu, Y.; Xu, H.; Han, T. Design and implementation of food supply chain traceability system based on hyperledger fabric. Int. J. Comput. Sci. Eng. 2020, 23, 185-193. [CrossRef]

62. Grecuccio, J.; Giusto, E.; Fiori, F.; Rebaudengo, M. Combining blockchain and iot: Food-chain traceability and beyond. Energies 2020, 13, 3820. [CrossRef]

63. Zhang, Y.; Liu, Y.; Jiong, Z.; Zhang, X.; Li, B.; Chen, E. Development and assessment of blockchain-IoT-based traceability system for frozen aquatic product. J. Food Process Eng. 2021, 44, e13669. [CrossRef]

64. Zhang, X.; Sun, P.; Xu, J.; Wang, X.; Yu, J.; Zhao, Z.; Dong, Y. Blockchain-based safety management system for the grain supply chain. IEEE Access 2020, 8, 36398-36410. [CrossRef]

65. Kontopanou, M.; Tsoulfas, G.T. Promoting and mainstreaming sustainability practices in agri-food supply chains. Sci. Pap. Manag. Econ. Eng. Agric. Rural. Dev. 2021, 21, 331-337.

66. Chan, K.Y.; Abdullah, J.; Khan, A.S. A framework for traceable and transparent supply chain management for agri-food sector in malaysia using blockchain technology. Int. J. Adv. Comput. Sci. Appl. 2019, 10, 149-156. [CrossRef]

67. Hu, S.; Huang, S.; Huang, J.; Su, J. Blockchain and edge computing technology enabling organic agricultural supply chain: A framework solution to trust crisis. Comput. Ind. Eng. 2021, 153, 107079. [CrossRef]

68. Orjuela, K.G.; Gaona-García, P.A.; Marin, C.E.M. Towards an agriculture solution for product supply chain using blockchain: Case study Agro-chain with BigchainDB. Acta Agric. Scand. Sect. B Soil Plant Sci. 2021, 71, 1-16. [CrossRef]

69. Patel, H.; Shrimali, B. AgriOnBlock: Secured data harvesting for agriculture sector using blockchain technology. ICT Express 2021, in press. [CrossRef]

70. Monteiro, E.S.; Righi, R.D.R.; Barbosa, J.L.V.; Alberti, A.M. APTM: A model for pervasive traceability of agrochemicals. Appl. Sci. 2021, 11, 8149. [CrossRef]

71. Patel, N.; Shukla, A.; Tanwar, S.; Singh, D. KRanTi: Blockchain-based farmer's credit scheme for agriculture-food supply chain. Trans. Emerg. Telecommun. Technol. 2021, early view. [CrossRef]

72. Pranto, T.H.; Noman, A.A.; Mahmud, A.; Haque, A.B. Blockchain and smart contract for IoT enabled smart agriculture. PeerJ Comput. Sci. 2021, 7, e407. [CrossRef]

73. Salah, K.; Nizamuddin, N.; Jayaraman, R.; Omar, M. Blockchain-Based Soybean Traceability in Agricultural Supply Chain. IEEE Access 2019, 7, 73295-73305. [CrossRef]

74. Shahid, A.; Almogren, A.; Javaid, N.; Al-Zahrani, F.A.; Zuair, M.; Alam, M. Blockchain-Based Agri-Food Supply Chain: A Complete Solution. IEEE Access 2020, 8, 69230-69243. [CrossRef]

75. Surasak, T.; Wattanavichean, N.; Preuksakarn, C.; Huang, S.C.H. Thai agriculture products traceability system using blockchain and Internet of Things. Int. J. Adv. Comput. Sci. Appl. 2019, 10, 578-583. [CrossRef]

76. Wang, L.; Xu, L.; Zheng, Z.; Liu, S.; Li, X.; Cao, L.; Li, J.; Sun, C. Smart Contract-Based Agricultural Food Supply Chain Traceability. IEEE Access 2021, 9, 9296-9307. [CrossRef]

77. Yang, X.; Li, M.; Yu, H.; Wang, M.; Xu, D.; Sun, C. A Trusted Blockchain-Based Traceability System for Fruit and Vegetable Agricultural Products. IEEE Access 2021, 9, 36282-36293. [CrossRef]

78. Yiu, N.C.K. Decentralizing supply chain anti-counterfeiting and traceability systems using blockchain technology. Future Internet 2021, 13, 84. [CrossRef]

79. Sunny, J.; Undralla, N.; Madhusudanan Pillai, V. Supply chain transparency through blockchain-based traceability: An overview with demonstration. Comput. Ind. Eng. 2020, 150, 106895. [CrossRef]

80. Panda, S.K.; Satapathy, S.C. Drug traceability and transparency in medical supply chain using blockchain for easing the process and creating trust between stakeholders and consumers. Pers. Ubiquitous Comput. 2021, 1-17. [CrossRef]

81. Fernando, E.; Meyliana, H.L.H.S.W.; Abdurachman, E. Blockchain technology for tracing drug with a multichain platform: Simulation method. Adv. Sci. Technol. Eng. Syst. 2021, 6, 765-769. [CrossRef]

82. Liu, X.; Barenji, A.V.; Li, Z.; Montreuil, B.; Huang, G.Q. Blockchain-based smart tracking and tracing platform for drug supply chain. Comput. Ind. Eng. 2021, 161, 107669. [CrossRef]

83. Musamih, A.; Jayaraman, R.; Salah, K.; Hasan, H.R.; Yaqoob, I.; Al-Hammadi, Y. Blockchain-Based Solution for the Administration of Controlled Medication. IEEE Access 2021, 9, 145397-145414. [CrossRef]

84. Musamih, A.; Salah, K.; Jayaraman, R.; Arshad, J.; Debe, M.; Al-Hammadi, Y.; Ellahham, S. A blockchain-based approach for drug traceability in healthcare supply chain. IEEE Access 2021, 9, 9728-9743. [CrossRef]

85. Zhu, P.; Hu, J.; Zhang, Y.; Li, X. A blockchain based solution for medication anti-counterfeiting and traceability. IEEE Access 2020, 8, 184256-184272. [CrossRef]

86. Uddin, M. Blockchain Medledger: Hyperledger fabric enabled drug traceability system for counterfeit drugs in pharmaceutical industry. Int. J. Pharm. 2021, 597, 120235. [CrossRef] [PubMed]

87. Ahmed, M.; Taconet, C.; Ould, M.; Chabridon, S.; Bouzeghoub, A. IoT data qualification for a logistic chain traceability smart contract. Sensors 2021, 21, 2239. [CrossRef]

88. Adarsh, S.; Joseph, S.G.; John, F.; Lekshmi, B.M.; Asharaf, S. A Transparent and Traceable Coverage Analysis Model for Vaccine Supply-Chain Using Blockchain Technology. IT Prof. 2021, 23, 28-35. [CrossRef] 
89. Yong, B.; Shen, J.; Liu, X.; Li, F.; Chen, H.; Zhou, Q. An intelligent blockchain-based system for safe vaccine supply and supervision. Int. J. Inf. Manag. 2020, 52, 102024. [CrossRef]

90. Alkhader, W.; Alkaabi, N.; Salah, K.; Jayaraman, R.; Arshad, J.; Omar, M. Blockchain-based traceability and management for additive manufacturing. IEEE Access 2020, 8, 188363-188377. [CrossRef]

91. Alkhader, W.; Salah, K.; Sleptchenko, A.; Jayaraman, R.; Yaqoob, I.; Omar, M. Blockchain-Based Decentralized Digital Manufacturing and Supply for COVID-19 Medical Devices and Supplies. IEEE Access 2021, 9, 137923-137940. [CrossRef]

92. Cao, Y.; Jia, F.; Manogaran, G. Efficient Traceability Systems of Steel Products Using Blockchain-Based Industrial Internet of Things. IEEE Trans. Ind. Inform. 2020, 16, 6004-6012. [CrossRef]

93. Kuhn, M.; Funk, F.; Zhang, G.; Franke, J. Blockchain-based application for the traceability of complex assembly structures. J. Manuf. Syst. 2021, 59, 617-630. [CrossRef]

94. Nazmul Islam, M.D.; Kundu, S. Enabling IC traceability via blockchain pegged to embedded PUF. ACM Trans. Des. Autom. Electron. Syst. 2019, 24, 1-23. [CrossRef]

95. Cui, P.; Dixon, J.; Guin, U.; Dimase, D. A Blockchain-Based Framework for Supply Chain Provenance. IEEE Access 2019, 7, 157113-157125. [CrossRef]

96. Omar, A.S.; Basir, O. Decentralized Identifiers and Verifiable Credentials for Smartphone Anticounterfeiting and Decentralized IMEI Database. Can. J. Electr. Comput. Eng. 2020, 43, 174-180. [CrossRef]

97. Suhail, S.; Hussain, R.; Khan, A.; Hong, C.S. Orchestrating product provenance story: When IOTA ecosystem meets electronics supply chain space. Comput. Ind. 2020, 123, 103334. [CrossRef]

98. Agrawal, T.K.; Kumar, V.; Pal, R.; Wang, L.; Chen, Y. Blockchain-based framework for supply chain traceability: A case example of textile and clothing industry. Comput. Ind. Eng. 2021, 154, 107130. [CrossRef]

99. Ho, G.T.S.; Tang, Y.M.; Tsang, K.Y.; Tang, V.; Chau, K.Y. A blockchain-based system to enhance aircraft parts traceability and trackability for inventory management. Expert Syst. Appl. 2021, 179, 115101. [CrossRef]

100. Lu, D.; Moreno-Sanchez, P.; Mitra, P.; Feldman, K.; Fodale, J.; Kosofsky, J.; Kate, A. Toward Privacy-Aware Traceability for Automotive Supply Chains. SAE Int. J. Transp. Cybersecur. Priv. 2021, 4, 61-82. [CrossRef]

101. Wang, Z.; Wang, T.; Hu, H.; Gong, J.; Ren, X.; Xiao, Q. Blockchain-based framework for improving supply chain traceability and information sharing in precast construction. Autom. Constr. 2020, 111, 103063. [CrossRef]

102. Čižmešija, A.; Vrček, N. Organizational Challenges of Blockchain Adoption: An Exploratory Literature Review. In Proceedings of the 2021 IEEE Technology Engineering Management Conference-Europe (TEMSCON-EUR), Dubrovnik, Croatia, 17-20 May 2021; pp. 1-6. [CrossRef]

103. Papathanasiou, A.; Cole, R.; Murray, P. The (non-)application of blockchain technology in the Greek shipping industry. Eur. Manag. J. 2020, 38, 927-938. [CrossRef]

104. Mai, N.; Bogason, S.; Arason, S.; Árnason, S.; Matthíasson, T. Benefits of traceability in fish supply chains-Case studies. Br. Food J. 2010, 112, 976-1002. [CrossRef]

105. Tönnissen, S.; Teuteberg, F. Using blockchain technology for business processes in purchasing- concept and case study-based evidence. In International Conference on Business Information Systems; Springer: Berlin/Heidelberg, Germany, 2018 ; pp. 253-264.

106. Zheng, Z.; Xie, S.; Dai, H.N.; Chen, W.; Chen, X.; Weng, J.; Imran, M. An overview on smart contracts: Challenges, advances and platforms. Future Gener. Comput. Syst. 2020, 105, 475-491. [CrossRef]

107. Aquilina, S.J.; Casino, F.; Vella, M.; Ellul, J.; Patsakis, C. EtherClue: Digital investigation of attacks on Ethereum smart contracts. Blockchain Res. Appl. 2021, 2, 100028. [CrossRef]

108. Negka, L.D.; Spathoulas, G.P. Blockchain State Channels: A State of the Art. IEEE Access 2021, 9, 160277-160298. [CrossRef]

109. Politou, E.; Casino, F.; Alepis, E.; Patsakis, C. Blockchain mutability: Challenges and proposed solutions. IEEE Trans. Emerg. Top. Comput. 2019, 9, 1972-1986. [CrossRef]

110. Casino, F.; Politou, E.; Alepis, E.; Patsakis, C. Immutability and decentralized storage: An analysis of emerging threats. IEEE Access 2019, 8, 4737-4744. [CrossRef]

111. Politou, E.; Alepis, E.; Patsakis, C.; Casino, F.; Alazab, M. Delegated content erasure in IPFS. Future Gener. Comput. Syst. 2020, 112, 956-964. [CrossRef]

112. Li, X.; Jiang, P.; Chen, T.; Luo, X.; Wen, Q. A survey on the security of blockchain systems. Future Gener. Comput. Syst. 2020, 107, 841-853. [CrossRef]

113. Banerjee, A. Blockchain technology: Supply chain insights from ERP. In Advances in Computers; Elsevier: Amsterdam, The Netherlands, 2018; Volume 111, pp. 69-98.

114. Powell, W.; Foth, M.; Cao, S.; Natanelov, V. Garbage in garbage out: The precarious link between IoT and blockchain in food supply chains. J. Ind. Inf. Integr. 2022, 25, 100261. [CrossRef]

115. Zachariadis, M.; Hileman, G.; Scott, S. Governance and control in distributed ledgers: Understanding the challenges facing blockchain technology in financial services. Inf. Organ. 2019, 29, 105-117. CrossRef]

116. Pelt, R.v.; Jansen, S.; Baars, D.; Overbeek, S. Defining Blockchain Governance: A Framework for Analysis and Comparison. Inf. Syst. Manag. 2021, 38, 21-41. [CrossRef]

117. Lumineau, F.; Wang, W.; Schilke, O. Blockchain governance-A new way of organizing collaborations? Organ. Sci. 2021, 32, 500-521. [CrossRef] 
118. Behnke, K.; Janssen, M.F.W.H.A. Boundary conditions for traceability in food supply chains using blockchain technology. Int. J. Inf. Manag. 2020,52, 101969. [CrossRef]

119. Graneheim, U.H.; Lindgren, B.M.; Lundman, B. Methodological challenges in qualitative content analysis: A discussion paper. Nurse Educ. Today 2017, 56, 29-34. [CrossRef] [PubMed] 